\title{
Fueled by methane: deep-sea sponges from asphalt seeps gain their nutrition from methane-oxidizing symbionts
}

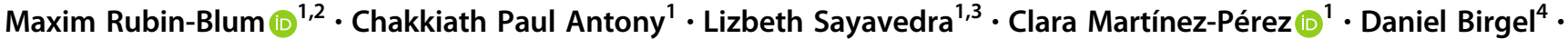 \\ Jörn Peckmann $\mathbb{1}^{4} \cdot$ Yu-Chen $\mathrm{Wu}^{5} \cdot$ Paco Cardenas $\mathbb{1}^{6} \cdot \operatorname{lan}$ MacDonald ${ }^{7} \cdot$ Yann Marcon $\mathbb{1}^{8} \cdot$ Heiko Sahling ${ }^{9}$. \\ Ute Hentschel $\left.\right|^{5} \cdot$ Nicole Dubilier $^{1,9}$
}

Received: 11 June 2018 / Revised: 16 December 2018 / Accepted: 20 December 2018 / Published online: 15 January 2019

(c) The Author(s) 2019. This article is published with open access

\begin{abstract}
Sponges host a remarkable diversity of microbial symbionts, however, the benefit their microbes provide is rarely understood. Here, we describe two new sponge species from deep-sea asphalt seeps and show that they live in a nutritional symbiosis with methane-oxidizing (MOX) bacteria. Metagenomics and imaging analyses revealed unusually high amounts of MOX symbionts in hosts from a group previously assumed to have low microbial abundances. These symbionts belonged to the Marine Methylotrophic Group 2 clade. They are host-specific and likely vertically transmitted, based on their presence in sponge embryos and streamlined genomes, which lacked genes typical of related free-living MOX. Moreover, genes known to play a role in host-symbiont interactions, such as those that encode eukaryote-like proteins, were abundant and expressed. Methane assimilation by the symbionts was one of the most highly expressed metabolic pathways in the sponges. Molecular and stable carbon isotope patterns of lipids confirmed that methane-derived carbon was incorporated into the hosts. Our results revealed that two species of sponges, although distantly related, independently established highly specific, nutritional symbioses with two closely related methanotrophs. This convergence in symbiont acquisition underscores the strong selective advantage for these sponges in harboring MOX bacteria in the food-limited deep sea.
\end{abstract}

Deceased: Heiko Sahling, 23 April 2018.

Supplementary information The online version of this article (https:// doi.org/10.1038/s41396-019-0346-7) contains supplementary material, which is available to authorized users.

$\triangle$ Maxim Rubin-Blum

mrubin@ocean.org.il

$\triangle$ Nicole Dubilier

ndubilie@mpi-bremen.de

1 Max Planck Institute for Marine Microbiology, Celsiusstrasse 1, 28359 Bremen, Germany

2 Israel Limnology and Oceanography Research, Tel Shikmona, 3108000 Haifa, Israel

3 Quadram Institute Bioscience, Norwich Research Park, Norwich, UK

4 Institute for Geology, Center for Earth System Research and Sustainability, University of Hamburg, 20146 Hamburg, Germany

\section{Introduction}

Symbioses with microorganisms have played a central role in shaping the ecology and evolution of marine animals [1]. Sponges are one of the oldest animal phyla and may have lived in symbiosis with microbial partners for hundreds of million years [2-4]. Most sponge species belong to one of two general categories: High microbial abundance (HMA)

5 GEOMAR Helmholtz Centre for Ocean Research, RD3 Marine Microbiology and Christian-Albrechts University of Kiel, Düsternbrooker Weg 20, D-24105 Kiel, Germany

6 Department of Medicinal Chemistry, Pharmacognosy, BioMedical Centre, Uppsala University, Husargatan 3, 75123 Uppsala, Sweden

7 Florida State University, POB 3064326, Tallahassee, FL 32306, USA

8 Wegener Institute Helmholtz Centre for Polar and Marine Research, HGF-MPG Group for Deep Sea Ecology and Technology, Am Handelshafen 12, 27570 Bremerhaven, Germany

9 MARUM, Center for Marine Environmental Sciences, University of Bremen, 28359 Bremen, Germany 
sponges such as those from the orders Agelasida and Verongida harbor dense microbial consortia with high phylogenetic diversity, while low microbial abundance (LMA) sponges such as those from the order Poecilosclerida have several orders of magnitude fewer symbionts with low phylogenetic diversity [5]. In both HMA and LMA sponges, the microbial symbionts are hypothesized to increase their host's fitness, for example by recycling nutrients and producing secondary metabolites that can deter predators $[4$, 6-8]. To date, the functional diversity of microorganisms associated with sponges has been studied primarily in hosts from shallow-water habitats, using metagenomics [9-15], proteomics [16], and transcriptomics [17-21]. However, the remarkable diversity of the microbiota in most shallowwater sponges [3] has made it highly challenging to understand their functional and ecological role. Even less is known about the metabolism, ecology, and evolutionary history of the microorganisms that live in symbiosis with deep-sea sponges.

In the deep sea, light is insufficient to sustain photosynthetic primary production, the input of particulate organic carbon from the surface is low, and nutrition is often limited [22]. While shallow-water sponges primarily gain their nutrition by filter-feeding on planktonic microorganisms and organic matter [4], some sponges have adapted to the deep sea, where low amounts of particulate organic carbon make filter-feeding energetically unfavorable, by becoming carnivores [23-25]. Sponges from cold seeps and hydrothermal vents in the deep sea may have evolved an alternative nutritional strategy. In these environments, abundant chemosynthetic primary production is fueled by reduced energy sources. Analyses of microbial communities based on metagenomics and 16S rRNA gene amplicon sequencing, as well as carbon stable isotope values, indicated that sponges from seeps are associated with chemosynthetic and hydrocarbon-degrading bacteria [25-30]. Thus, in addition to filter-feeding or carnivory, these sponges could gain a considerable proportion of their nutrition from chemosynthetic symbionts.

In contrast to the well-studied chemosynthetic symbioses of more highly evolved invertebrate groups such as bivalves and annelids [31], little is known about these associations in sponges. To gain a better understanding of chemosynthetic symbioses in deep-sea sponges, we used metagenomics, metatranscriptomics, fluorescence, and electron microscopy, as well as lipid (fatty acids and sterols) and stable isotope analyses to study two sponge species from hydrocarbon seeps at Campeche Knolls at 2900-3100 m depth in the southern Gulf of Mexico. These sites are characterized by prolific asphalt flows, oil seepage, gas hydrates, and gas venting [32]. Campeche sponges were previously shown to host hydrocarbon-degrading Cycloclasticus bacteria, but these make up only about $5 \%$ of their bacterial community [33]. The majority of the sponge microbiota $(50-70 \%)$ was dominated by methane-oxidizing (MOX) bacteria (the abbreviation MOX is also used for methane oxidizer(s) in the following), [33]. In this study, we provide in-depth insights into the symbiosis between sponges from the Campeche seeps and their MOX bacteria, with the goal of better understanding the evolutionary history and physiology of the MOX symbionts, revealing the mechanisms that might determine the specificity of the sponge-MOX association, comparing the genomic potential of the symbiotic MOX with that of free-living MOX, and tracing the incorporation of methane-derived carbon into sponge biomass.

\section{Materials and methods}

\section{Sample collection}

Sponges were collected with the remotely-operated vehicle MARUM-QUEST during the RV Meteor M114-2 cruise to the Campeche Knolls in March 2015. The sponges were collected by placing asphalt pieces on which they grew in an insulated polypropylene "bio-box" to protect against temperature changes during the ascension of the ROV to warm surface waters (ascension time from seafloor to onboard ship $\sim 2 \mathrm{~h}$ ). We sampled two encrusting sponge individuals, one from Chapopote Knoll $\left(21^{\circ} 54^{\prime} \mathrm{N} ; 93^{\circ} 26^{\prime} \mathrm{W}, 2925 \mathrm{~m}\right.$ water depth) and one from Mictlan Knoll $\left(22^{\circ} 1^{\prime}\right.$ N; $93^{\circ} 14^{\prime}$ W, 3106 m water depth), which are $\sim 25 \mathrm{~km}$ apart from each other (Fig. 1). A third sponge individual with a branching morphology was collected from the same site at Chapopopote as the encrusting sponge. The sponges appeared healthy and intact before collection, with no evidence of tissue damage. A detailed description of the collection sites is available elsewhere [32]. Sponge distributions at Chapopote were estimated using mosaic mapping (see Supplementary Methods 4).

After ROV recovery, the asphalt pieces with the sponges were kept on board in the seawater from the "bio-box" at $4{ }^{\circ} \mathrm{C}$. For metagenomic and metatranscriptomic analyses, subsamples from each sponge individual were fixed on board $\sim 1 \mathrm{~h}$ after ROV recovery in RNAlater ${ }^{\circledR}$ (Sigma, Steinheim, Germany) according to the manufacturer's instructions and stored at $-80^{\circ} \mathrm{C}$. Subsamples for microscopy were fixed in $2 \%$ paraformaldehyde in $1 \mathrm{x}$ phosphatebuffered saline (PBS) for at most $12 \mathrm{~h}$ at $4{ }^{\circ} \mathrm{C}$, rinsed three times in $1 \mathrm{x}$ PBS, and stored at $4{ }^{\circ} \mathrm{C}$ in $0.5 \mathrm{x}$ PBS $/ 50 \%$ ethanol. Subsamples for transmission electron microscopy were fixed in PHEM buffer (PIPES, HEPES, EGTA and $\mathrm{MgCl}_{2}$, see ref. [34]). Samples for lipid biomarker 

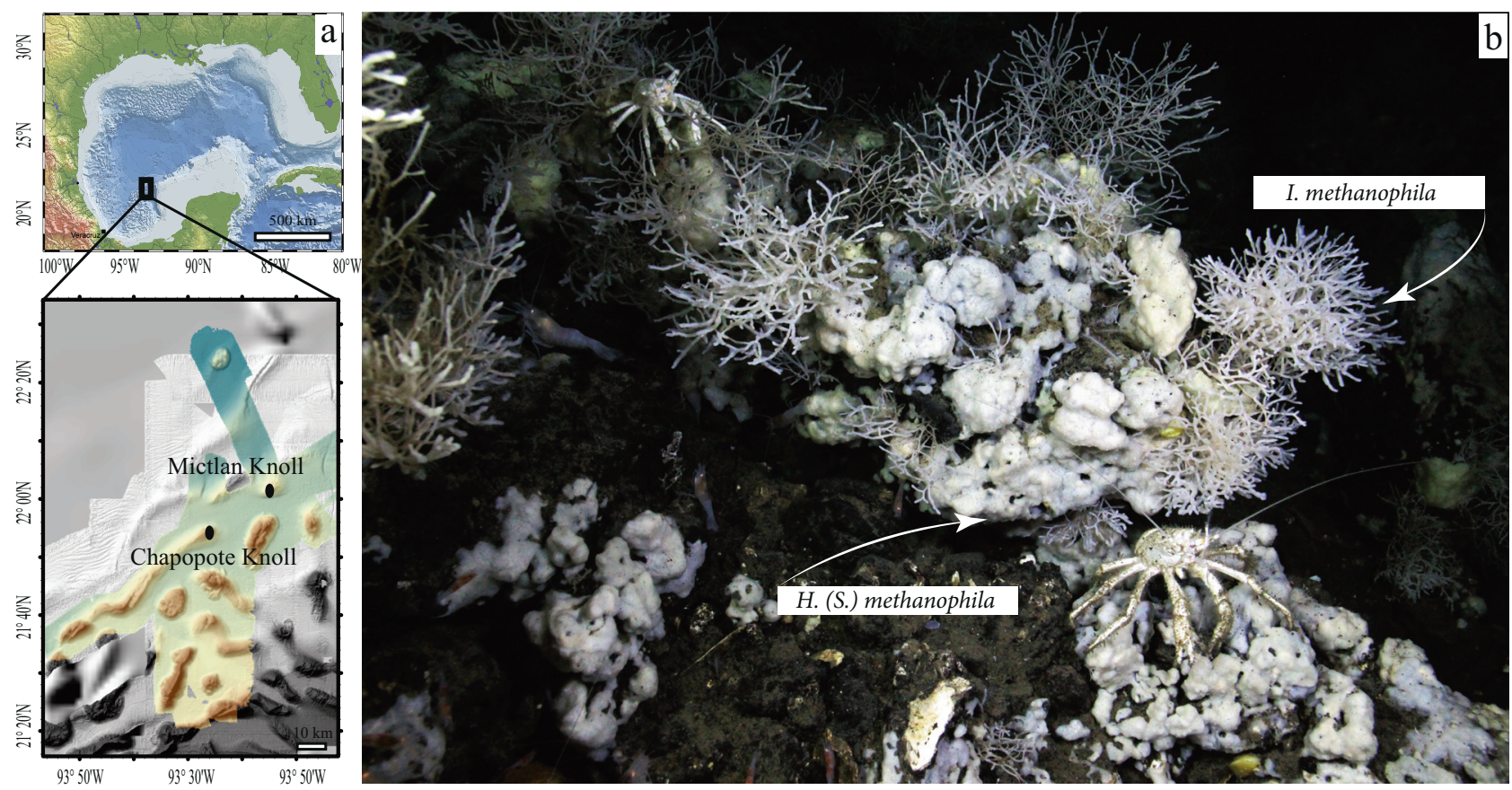

Fig. 1 The encrusting sponge Hymedesmia (Stylopus) methanophila sp. nov. and the branching sponge Iophon methanophila sp. nov. colonize asphalt seeps at Campeche Knolls. a Geographic location of
Campeche Knolls and the sponge collection sites, Chapopote and Mictlan. b MARUM-QUEST ROV image of $H$. (S.) methanophila and I. methanophila at Chapopote. Galatheid crabs graze on the sponges analysis were flash-frozen in liquid nitrogen and stored at $-80^{\circ} \mathrm{C}$.

\section{Fluorescence in situ hybridization (FISH)}

The probe used in this study, MTC849 probe (5'CGTTAGCTCCACCACTAAG-3'), was designed with ARB [35] to target the 16S rRNA gene sequences of the symbiotic MOX of both Campeche sponge species. This probe is a modification of MTC850 probe, designed to target Marine Methylotrophic Group (MMG) 2 MOX [36]. Apart from the symbiotic and MMG2 MOX, the MTC849 probe targets the closely related Methylomonas and Methylomarinum clades. The MTC849 oligonucleotide was double-labeled with Atto594 dye (Biomers, Ulm, Germany), and applied to $8 \mu \mathrm{m}$ sections of sponge tissue using hybridization buffer with $20 \%$ formamide as described previously [37]. These hybridization conditions are assumed to ensure specificity, given the three mismatches that the MTC849 probe had to the 16S rRNA gene sequences of all other Campeche sponge bacteria [38]. The general bacterial probe EUB338 [39] was used as a positive control and the NON338 probe was used as a control for background autofluorescence [40]. Photomicrographs were acquired with a Zeiss Axioplan 2 epifluorescence microscope (Zeiss, Jena, Germany) or with a confocal laserscanning microscope (LSM 780, Carl Zeiss, Germany). Brightness and contrast of the images were adjusted with Adobe Photoshop (Adobe Systems, Inc., USA).

\section{Transmission electron microscopy (TEM)}

Subsamples of the two encrusting and one branching sponge individuals were washed with $50 \mathrm{mM}$ cacodylate buffer, post-fixed with $2 \%$ osmium tetroxide in the buffer for $1.5 \mathrm{~h}$ at $4{ }^{\circ} \mathrm{C}$, and then washed with Milli-Q water. Following overnight staining in $0.5 \%$ uranyl acetate (Merck, Germany), the samples were washed with Milli-Q water, dehydrated in a graded ethanol series, and then transferred into propylene oxide (Sigma-Aldrich, Germany). The samples were infiltrated with Epon-812 resin (1:1 resin to propylene oxide) overnight and rinsed in this resin twice for $2 \mathrm{~h}$. They were then transferred into fresh resin for $1 \mathrm{~h}$ and polymerized in embedding capsules at $60{ }^{\circ} \mathrm{C}$ for at least $48 \mathrm{~h}$. Ultrathin $(70 \mathrm{~nm})$ sections were cut with an ultramicrotome (Leica EM UC7, Austria), mounted on pioloform coated grids, and contrasted with $2.5 \%$ uranyl acetate in ethanol for 20 min and subsequently, with Reynold's lead citrate for $10 \mathrm{~min}$. Ultrathin sections were imaged at $80 \mathrm{kV}$ on a Tecnai G2 Spirit BioTwin transmission electron microscope (FEI Company, USA). We were able to produce high-quality micrographs of the two encrusting sponge individuals, but not of the branching sponge individual.

\section{DNA and RNA extraction and sequencing}

We extracted DNA and RNA from the two encrusting sponge individuals and from two different branches of the 
same branching sponge individual. DNA and RNA were extracted in parallel with the AllPrep DNA/RNA Mini Kit (Qiagen, Hilden, Germany) according to the manufacturer's recommendations, with an extra DNase I digestion step on RNA columns to eliminate contaminating DNA. DNA/ RNA quality was assessed with the Agilent 2100 Bioanalyzer (Agilent, Santa Clara, USA). We were not able to extract RNA in sufficient amounts for transcriptomic analyses of the branching sponge individual. cDNA was synthesized with Ovation RNA-Seq System V2 (NuGen, San Carlos, CA, USA). Genomic DNA and cDNA libraries were generated with the DNA library prep kit for Illumina (BioLABS, Frankfurt am Main, Germany). All samples were sequenced on the Illumina HiSeq 2500 platform at the Max Planck Genome Centre (Cologne). For one subsample of the branching sponge, 41 million $150 \mathrm{bp}$ paired-end metagenomic reads were generated. For the remaining three libraries, 12.5 million $250 \mathrm{bp}$ paired-end metagenomic reads were generated, while the remaining 15.5-29.5 million were generated as $150 \mathrm{bp}$ paired-end reads. In total, 30 and 38 million $100 \mathrm{bp}$ paired-end cDNA reads were generated from the Mictlan and Chapopote encrusting sponge RNA extracts, respectively.

\section{Genome analyses}

Individual metagenomes were assembled with IDBA-UD [41], following decontamination, quality filtering $(\mathrm{QV}=$ 2) and adapter-trimming with the BBDuk tool from the BBMap suite (Bushnell B, http://sourceforge.net/projects/ bbmap/). Individual symbiont genomes were binned based on genome coverage, GC content and taxonomic affiliation using gbtools (Supplementary Figure S1) [42]. These bins were reassembled with Spades V3.10 [43, 44], using a maximum k-mer length of 127 , following remapping of Illumina reads to the bins using BBMap with 0.98 minimum identity. Following the manual removal of contigs shorter than $800 \mathrm{bp}$ and contamination screening, quality metrics were calculated with Quast [45] and CheckM [46]. Symbiont draft genomes and transcriptome reads were deposited in NCBI under accession numbers PRJNA475438 and PRJNA475442. Downstream genome analyses are summarized in Supplementary Methods S1.

\section{Transcriptome analyses}

Adapters and ribosomal RNA genes were removed from transcriptome reads with BBDuk. Transcriptome reads were mapped to the individual methanotroph genome assemblies with BBMap (minimum identity value of 0.98 ). Mapped reads were assigned to genomic features with featureCounts [47]. Relative RNA levels were estimated with transcripts per million (TPM) normalization [48]. The metatranscriptomes were assembled with Trinity [49] and the transcripts were quantified with an align_and_estimate_abundance.pl script from the Trinity package, using RSEM quantification method [50].

\section{Phylogenomics}

Phylogenomic reconstructions were performed with phylogenomics-tools scripts (https://doi.org/10.5281/ zenodo.46122). Marker proteins that are universally conserved across the bacterial domain were extracted from genomes using AMPHORA2 [51]. Eighteen single-copy markers that were present in all genomes analyzed in this study were used for alignment with MUSCLE [52]. The marker alignments were concatenated into a single partitioned alignment. Poorly aligned or misaligned regions were removed from the alignments. The maximum likelihood tree was calculated with MEGA7 [53] using the LG model [54].

\section{Lipid biomarker analysis}

Lipid biomarkers were extracted from one individual of branching and one individual of encrusting sponge (both collected at Chapopote). Phospholipid fatty acids were hydrolyzed by saponification with $6 \% \mathrm{KOH}$ in methanol. Sterols were extracted with dichloromethane:methanol (3:1) three times. The resulting total lipid extract and the saponification extract were combined. The hydrolyzed free fatty acid salts were released from the aqueous phase by adding $\mathrm{HCl}$ until $\mathrm{pH}$ 2. Then, the combined extracts were separated by solid phase column chromatography into four fractions. The resulting fatty acids and the alcohols were analyzed on a Thermo Electron Trace DSQ II coupled gas-chromatographmass spectrometer (GC-MS) for quantification and identification. The GC-MS was equipped with a $30 \mathrm{~m}$ HP-5 MS UI fused silica capillary column $(0.25 \mathrm{~mm}$ i.d., $0.25 \mu \mathrm{m}$ film thickness). The carrier gas was helium. The GC temperature program used for both fractions was as follows: $60^{\circ} \mathrm{C}(1$ min), from 60 to $150{ }^{\circ} \mathrm{C}$ at $10^{\circ} \mathrm{min}$, from 150 to $325^{\circ} \mathrm{C}$ at 4 ${ }^{\circ} \mathrm{C} / \mathrm{min}, 25 \mathrm{~min}$ isothermal. Identification of compounds was based on retention times and published mass spectral data. Double bond positions of unsaturated fatty acids were identified by the addition of a dimethyl disulfide (DMDS) adduct to an aliquot of the saponified fatty acid fraction [55]. Further, compound-specific carbon stable isotope compositions of fatty acids and sterols were measured on a gas chromatograph (Agilent 6890) coupled with a Thermo Finnigan Combustion III interface to a Finnigan Delta Plus XL isotope ratio mass spectrometer (GC-IRMS). The GC conditions were identical to those mentioned above for GC-MS analyses. 
Table 1 Relative abundance and phylogenetic assignment of sponge-associated bacteria based on metagenomic and metatranscriptomic coverage of their 16S rRNA gene sequences and the coverage of metagenome assembled genomes (MAGs)

\begin{tabular}{|c|c|c|c|c|c|c|c|c|c|c|}
\hline & \multicolumn{6}{|c|}{ 16S rRNA gene coverage } & \multicolumn{4}{|c|}{ average MAG coverage } \\
\hline & \multicolumn{4}{|c|}{ DNA } & \multicolumn{2}{|c|}{ RNA } & \multirow[b]{2}{*}{ HmetMict } & \multirow[b]{2}{*}{ HmetChap } & \multirow[b]{2}{*}{ ImetChap1 } & \multirow[b]{2}{*}{ ImetChap2 } \\
\hline & $\begin{array}{c}\text { HmetMict } \\
(2.7)\end{array}$ & $\begin{array}{c}\text { HmetChap } \\
(1.0)\end{array}$ & $\begin{array}{c}\text { ImetChap1 } \\
(0.4)\end{array}$ & $\begin{array}{c}\text { ImetChap2 } \\
(0.8)\end{array}$ & $\begin{array}{c}\text { HmetMict } \\
(1.6)\end{array}$ & $\begin{array}{c}\text { HmetChap } \\
(5.6)\end{array}$ & & & & \\
\hline MOX (MMG2, Proteobacteria) & 58.8 & 50.4 & 58.1 & 52.5 & 42.8 & 37.6 & 67.6 & 52.1 & 45.3 & 35.9 \\
\hline $\begin{array}{l}\text { Thioglobaceae - SUP05 } \\
\text { (Proteobacteria) }\end{array}$ & 5.7 & 6.9 & 12.4 & 14.8 & 6.8 & 7.3 & 4.6 & 5.2 & 17.0 & 20.2 \\
\hline Cycloclasticus (Proteobacteria) & 10.8 & 6.2 & 6.5 & 5.1 & 8.9 & 1.8 & 7.9 & 8.4 & 6.7 & 6.0 \\
\hline $\begin{array}{l}\text { E01-9C-26 marine group }{ }^{\mathrm{a}} \\
\text { (Proteobacteria) }\end{array}$ & 6.3 & 14.8 & 0.6 & 0 & 10.0 & 10.0 & 14.8 & 21.6 & 0 & 0 \\
\hline JTB23 (Proteobacteria) & 10.9 & 11.9 & 10.7 & 12.9 & 8.5 & 5.3 & 1.4 & 4.3 & 15.1 & 18.7 \\
\hline $\begin{array}{l}\text { Nitrosopumilus } \\
\text { (Thaumarchaeota) }\end{array}$ & 0.1 & 3.2 & 0 & 0.6 & 8.1 & 28.7 & 0.4 & 6.2 & 0 & 0.9 \\
\hline $\begin{array}{l}\text { Aqs2 Betaproteobacteria }{ }^{\text {}} \\
\text { (Proteobacteria) }\end{array}$ & 0 & 0 & 6.8 & 7.5 & 0 & 0 & 0 & 0 & 8.6 & 9.0 \\
\hline Cytophagales (Bacteroidetes) & 0 & 0 & 2.6 & 3.8 & 0 & 0 & 0 & 0 & 3.2 & 4.6 \\
\hline $\begin{array}{l}\text { BD7-8 marine group } \\
\text { (Proteobacteria) }\end{array}$ & 3.4 & 2.9 & 0 & 0 & 7.6 & 3.0 & 2.1 & 1.4 & 0 & 0 \\
\hline Endozoicomonas (Proteobacteria) & 2.1 & 1.2 & 3.2 & 2.1 & 3.2 & 2.1 & 0 & 0 & 0 & 0 \\
\hline KI89A clade ((Proteobacteria)) & 1.7 & 1.0 & 0.3 & 0.3 & 3.1 & 0.9 & 1.1 & 0.7 & 0.4 & 0.5 \\
\hline Azospirillum (Proteobacteria) & 0.2 & 1.0 & 0 & 0 & 0.9 & 2.6 & 0 & 0 & 0 & 0 \\
\hline Nitrospina (Nitrospinae) & 0 & 0.4 & 0 & 0 & 0.1 & 0.6 & 0 & 0 & 0 & 0 \\
\hline OCS116 (Proteobacteria)) & 0 & 0 & 1.5 & 1.3 & 0 & 0 & 0 & 0 & 2.0 & 2.1 \\
\hline SAR324 (Proteobacteria)) & 0 & 0 & 0.5 & 0.9 & 0 & 0 & 0 & 0 & 0.8 & 1.3 \\
\hline Spirochaetales (Spirochaetes) & 0 & 0 & 0.3 & 0.2 & 0 & 0 & 0 & 0 & 0.4 & 0.5 \\
\hline Bdellovibrio (Proteobacteria) & 0 & 0 & 0.3 & 0.2 & 0 & 0 & 0 & 0 & 0.3 & 0.2 \\
\hline
\end{tabular}

Classifications at the Phylum level are mentioned in parentheses. The 16S rRNA sequences of the MOX symbionts were identical within each host species, and differed slightly, but distinctly between the two host species (97.8\% identity). The following names are abbreviated: $H$. ( $S$.) methanophila from Mictlan (HmetMict) and Chapopote (HmetChap); I. methanophila from Chapopote subsamples 1 and 2 (ImetChap1 and ImetChap2); methane-oxidizing bacteria (MOX); marine methylotrophic group 2 (MMG2). Numbers in parentheses within the column headers represent the ratio between the MOX 16S and the host's 18S rRNA gene coverage

${ }^{a} \mathrm{E} 01-9 \mathrm{C}-26$ marine group is a monophyletic 'sponge-enriched' gammaproteobacterial clade

bAqs2 symbiont is a monophyletic 'sponge-enriched' clade of Proteobacteria, which includes symbionts of the low microbial abundance sponges Amphimedon queenslandica and Crambe crambe

\section{Results and Discussion}

\section{Novel sponge species are abundant at Chapopote}

Morphological analyses of both sponge morphotypes revealed that these have not yet been described. We name them here Hymedesmia (Stylopus) methanophila sp. nov. and Iophon methanophila sp. nov. (order Poecilosclerida). These belong to two different genera and are only distantly related to each other (based on $90 \%$ identity of their cytochrome c oxidase subunit I (COI) gene sequences). A full description of the morphology and phylogeny of these two sponge species is available in Supplementary File SF1.

At Chapopote and Mictlan, H. (S.) methanophila and I. methanophila occurred on fragmented asphalt accumulations next to sites of active seepage, characterized by gas and oil effusions and darkly colored substrates (Supplementary Figure S2). I. methanophila individuals were often observed growing on the tubes of tubeworms. Based on our mosaic mapping of the Chapopote site, we estimate that the sponges colonized $\sim 30 \%$ of the hard substrates in areas of active seepage (Supplementary Figure S2). We often observed grazers in association with the sponges, in particular, galatheid crabs (Fig. 1). These observations, together with observations of similar sponge abundances during a 2005 cruise to Chapopote [56], suggest that these sponges have made up a considerable part of the biomass at Chapopote for over twelve years, and are thus likely to influence the composition of the seep community and contribute to its food web. 


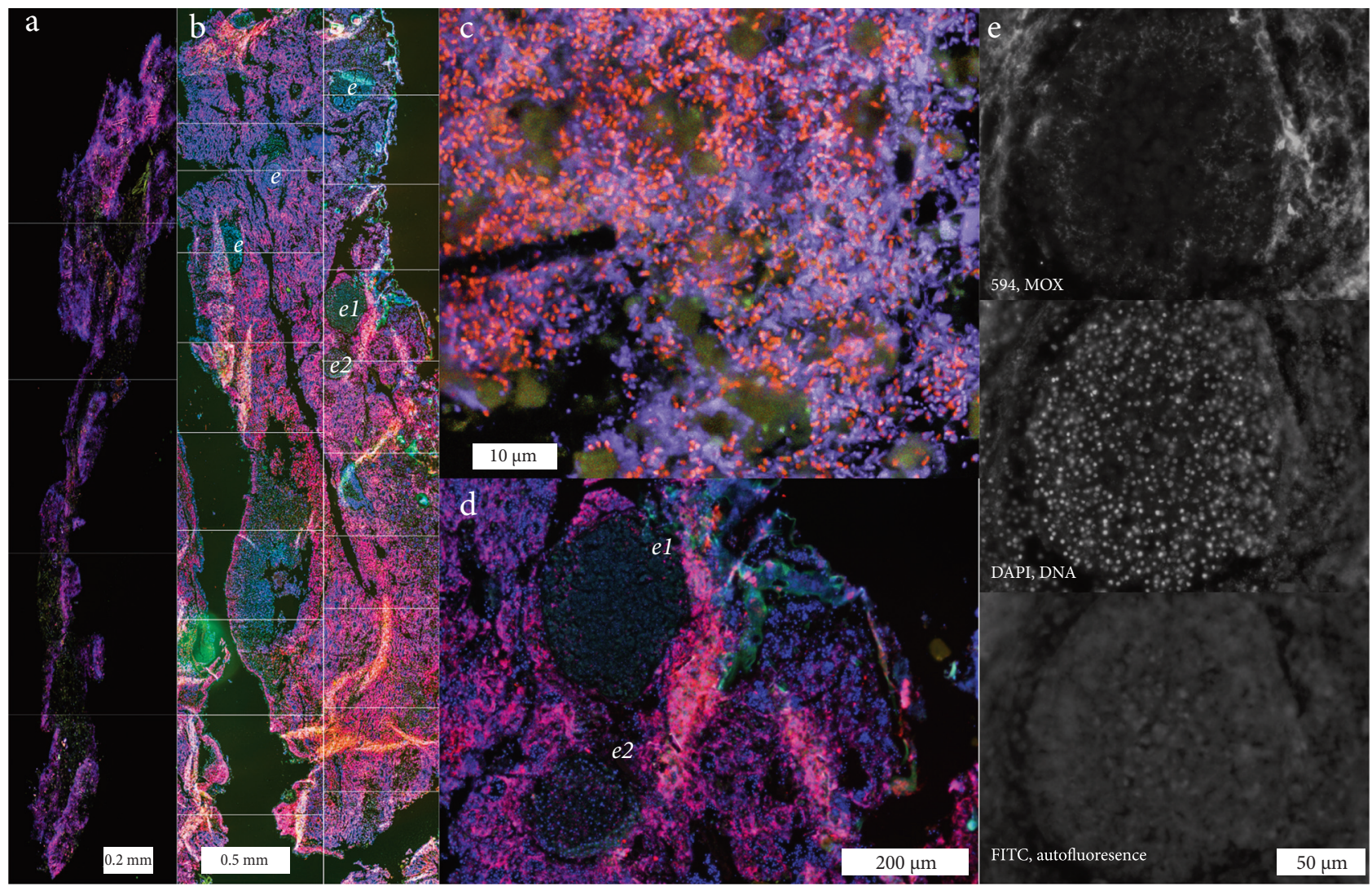

Fig. 2 Fluorescence in situ hybridization (FISH) images of the symbiotic methane-oxidizing bacteria (MOX) in Campeche sponges. FISH was performed with a probe specific to the symbiotic MOX on $10 \mu \mathrm{m}$ thick sections of I. methanophila and $H$. (S.) methanophila. Colors: MOX symbionts, magenta; DNA (DAPI staining), blue; autofluorescence at $\sim 520 \mathrm{~nm}$ with $\sim 490 \mathrm{~nm}$ excitation (FITC filter), green. a Overview of $I$. methanophila. The image is a mosaic of five aligned images (lines mark borders between the images). b Overview of $H$. (S.) methanophila. The image is a mosaic of twenty aligned images (lines mark borders between the images, $e$ : embryos in various developmental stages. c MOX

\section{Campeche sponges host high abundances of methane-oxidizing bacteria}

Analyses of the microbial communities hosted by $H$. (S.) methanophila and I. methanophila revealed that their dominant members were MOX (35.9-67.6\% of the microbial community; these values and the following in this paragraph are based on relative 16S rRNA read frequencies in the metagenomes, as well as the frequencies of metagenomic reads that mapped to the MOX genomes, see Supplementary Methods and Table 1). In both host species, Proteobacteria made up the vast majority of the microbial community (94.8-99.9\%), and included chemoautotrophic sulfur-oxidizing bacteria from the SUP05 clade (4.6$20.2 \%$ ) and hydrocarbon-degrading Cycloclasticus symbionts (6.0-8.4\%), which have been described elsewhere [33]. Such high abundances of Proteobacteria have not been commonly found in HMA sponges. Most HMA sponges symbionts are abundant in the mesohyl of I. methanophila. d Detail of embryos labeled $e 1$ and $e 2$ in panel (b). e FISH images of embryo labeled $e 2$ in panel (b) using gray intensity representation to distinguish FISH signal of MOX symbionts (top panel) from DAPI staining (middle panel) and autofluorescence (bottom panel). Images from the mosaics, additional images of MOX in tissues of $H$. (S.) methanophila embryos and 3-dimensional z-stack reconstructions are available at https://figsha re.com/projects/Fueled_by_methane_Deep-sea_sponges_from_asphalt_ seeps gain their_nutrition from methane-oxidizing_symbionts/23020

harbor highly diverse microbial communities that are often dominated by the bacterial phyla Chloroflexi, Acidobacteria, and Actinobacteria [57].

Although the low phylogenetic diversity of the microbial community in Campeche sponges is typical of LMA hosts, fluorescence in situ hybridization (FISH) revealed that the abundances of bacteria were more typical of HMA sponges [5] (Fig. 2). FISH with a probe specific to the MOX 16S rRNA sequences in both host species revealed that these bacteria were present in high numbers in the sponge mesohyl (the gelatinous matrix within a sponge that fills the space between its external and internal cell layers). Although the Campeche sponges belong to an order (Poecilosclerida) previously described as consisting of only LMA species, they have traits typical of both LMA sponges (low phylogenetic diversity) and HMA sponges (high symbiont abundances). They thus represent an exception to the described dichotomy between HMA and LMA sponges. 


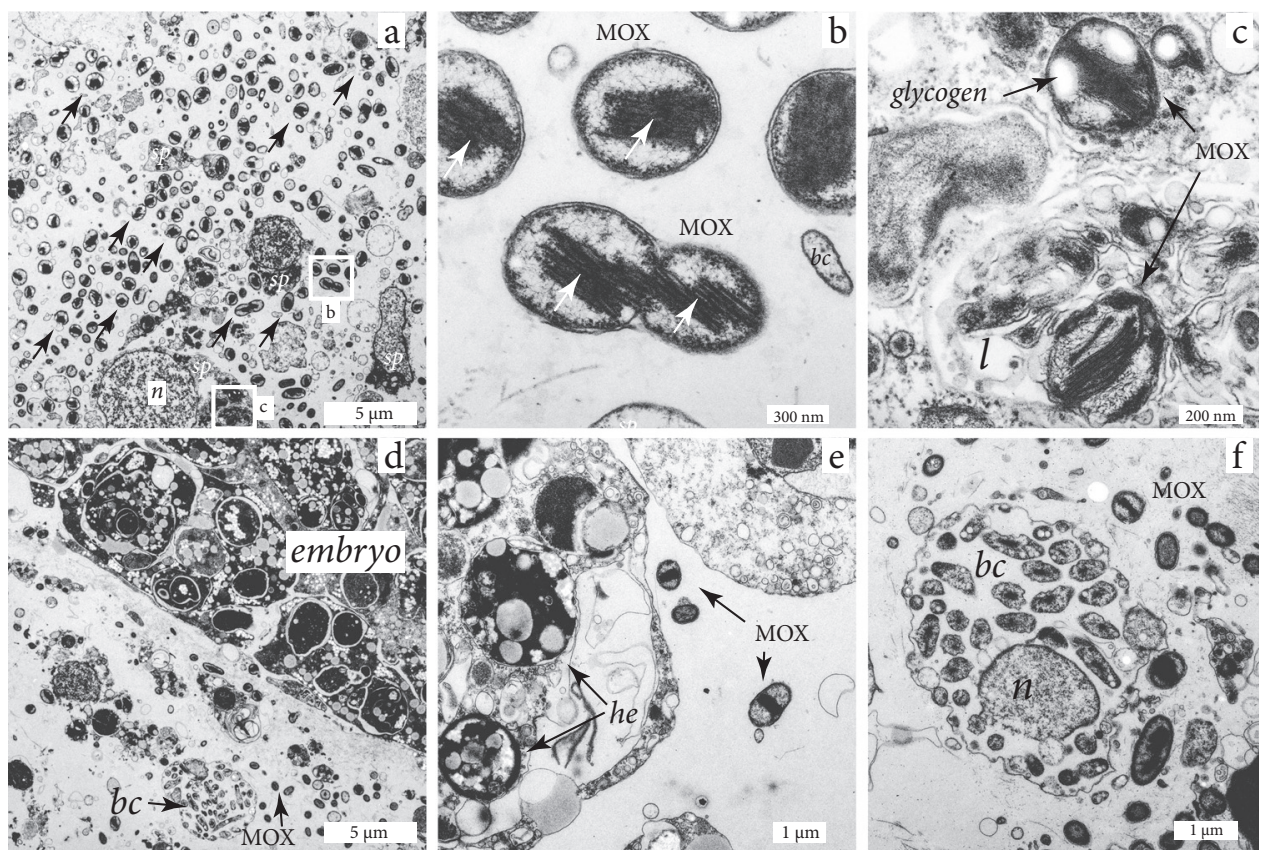

Fig. 3 Transmission electron microscopy images of $H$. (S.) methanophila. a Symbiotic methane-oxidizing bacteria (MOX) are abundant in the mesohyl, particularly in regions close to the choanocyte chambers (chambers not visible in image), $s p=$ sponge cells, $n=$ nucleus. b High-resolution image of white box labeled b from panel (a), showing intracellular membranes (arrows) typical for MOX. The MOX at the lower half of the image are dividing; $b c=$ bacteria with a

Transmission electron microscopy (TEM) of $H$. (S.) methanophila revealed that their mesohyl was colonized by a bacterial morphotype characterized by (i) a coccoid shape and intracytoplasmic membrane stacks typical of MOX bacteria; (ii) sizes of $500-1300 \mathrm{~nm}$ length and $500-900 \mathrm{~nm}$ width, and (iii) electron-lucent granules typical of storage compounds, most likely glycogen (Fig. 3a, Supplementary Note 1). The distribution pattern of these morphotypes was similar to that of the MOX bacteria identified with FISH, indicating that we could identify the MOX symbiont of $H$. (S.) methanophila with TEM based on its characteristic ultrastructure. We regularly observed MOX in stages of division, indicating that they were actively growing in the sponge matrix (Fig. 3b). The MOX were generally extracellular, but we occasionally found them within host vacuoles in different stages of degradation (Fig. 3c), indicating that the sponge cells engulf and digest these symbionts. Bacteria with a very different morphology than that of the MOX symbionts occurred in what looked like specialized bacteriocyte cells described from other sponge species $[58,59]$, but we never observed MOX in these host cells (Fig. 3f). The symbiotic MOX were most abundant in mesohyl regions near the choanocyte chambers (Fig. 3a). This indicates that the symbiotic MOX benefit from being close to the flagellated choanocytes, most likely because different morphology than the MOX symbionts. $\mathbf{c}$ MOX symbiont in a lysosome of an amebocyte, $l=$ lysosome. d Mesohyl with an embryo surrounded by symbiotic MOX, and a bacteriocyte containing bacteria with a different morphology than the symbiotic MOX $(b c)$. e MOX symbionts within an embryo. $h e=$ heterogeneous yolk. f A bacteriocyte containing bacteria with a different morphology than the MOX symbionts. $b c=$ bacteria; $n=$ nucleus

these host cells pump the methane- and oxygen-containing seawater from the seep environment into the sponge matrix, and thus provide the symbionts with the reductants and oxidants they need for their energy and carbon metabolism.

\section{Specificity of the sponge-MOX association}

The comparison of the MOX symbiont genomes from the two Campeche sponge species suggests that these are specific to their hosts. The two $H$. (S.) methanophila individuals that were collected $25 \mathrm{~km}$ apart at Chapopote and Mictlan, hosted nearly identical MOX genotypes (99.6 \pm $0.9 \%$ average nucleotide identity (ANI)). Only one $I$. methanophila individual could be collected from the Campeche seeps (at Chapopote), but ANI values of the MOX symbiont genomes from two different branches of this individual were nearly identical $(100 \pm 0.6 \%)$. Comparison of the MOX symbiont genomes from the sympatric $H$. (S.) methanophila and I. methanophila individuals, which were collected from the same asphalt piece at Chapopote, revealed that these differed considerably from each other $(93.6 \pm 2.5 \% \mathrm{ANI}$ ), and can be considered to belong to two different species (ANI $<95 \%$, [59]). These results suggest that each sponge species hosts a specific MOX genotype, and imply the presence of recognition and selection 


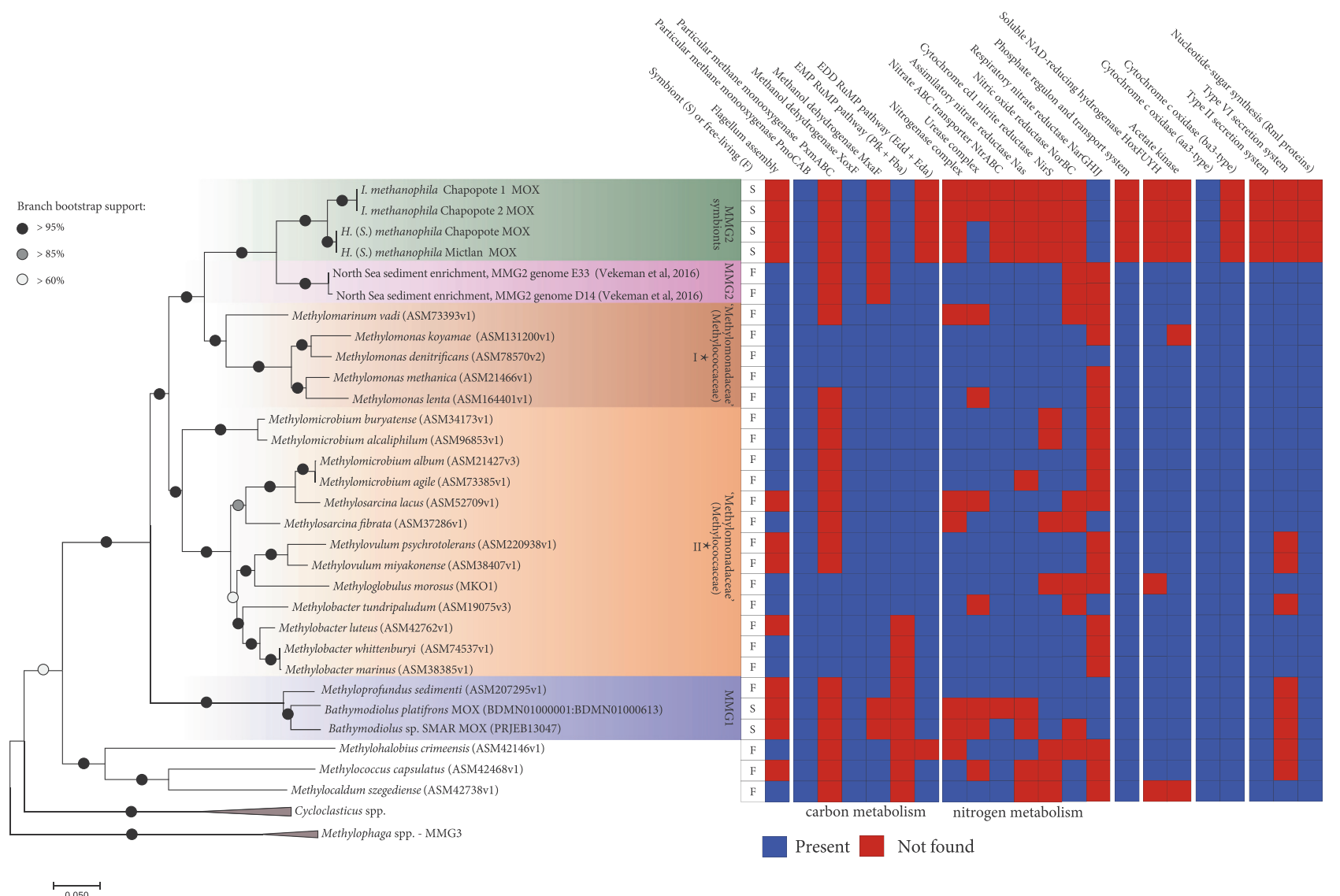

Fig. 4 Phylogenomic tree and metabolic repertoire of the sponge MOX symbionts and related bacteria (45 sequences total). The sponge MOX symbionts and the two free-living MOX from North Sea sediment enrichments (provided by B. Vekeman) are currently the only genomes available for the MMG (Marine Methylotrophic Group) 2, although $16 \mathrm{~S}$ rRNA data indicates that they are widespread (see Supplementary Figure S3 16S rRNA tree). Eighteen single-copy markers as defined in the AMPHORA core bacterial phylogenetic marker database were

mechanisms that underlie the potential specificity of this symbiosis.

\section{The symbiotic MOX belong to the Marine Methylotrophic Group 2 clade}

Phylogenomic reconstruction of eighteen marker proteins, as well as the phylogenies of 16S rRNA and pmoA (particulate methane monooxygenase) genes, revealed that the sponge-associated MOX belong to the Marine Methylotrophic Group (MMG) 2 clade (also known as deep-sea clade 2) within the family 'Methylomonadaceae', order Methylococcales (Fig. 4, Supplementary Figures S3 and S4) [61]. To date, there are no pure cultures of bacteria from the MMG2 clade, but recently the genomes of two MMG2 MOX enriched from North Sea sandy sediments with methane as the sole carbon and energy source were sequenced [62]. Together with the Campeche MOX used in the analysis. The tree is drawn to scale, with branch lengths representing the number of substitutions per site. The percentage of trees in which the associated taxa clustered together was determined based on 100 bootstrap resamples. The analysis included 3706 positions. *These clades were formerly included in the family Methylococcaceae, and recently placed together with the MMG1 and MMG2 clades within the family 'Methylomonadaceae' (order Methylococcales), based on the Genome Taxonomy Database symbionts, these are currently the only genomes that have been sequenced from the MMG2 clade.

Interestingly, MMG2 bacteria have been reported from other marine hosts based on 16S rRNA and pmoA gene sequencing, although their abundances appear to generally be considerably lower than in the Campeche sponges (Supplementary Figures S3 and S4). MMG2-related sequences were described from ciliates collected at methane seeps along the eastern Pacific coast (1.7-9.7\% of the ciliate bacterial community based on 16S rRNA tag sequencing) [63], and the squat lobster Shinkaia crosnieri from hydrothermal vents off Japan (1.7-12.0\% of $16 \mathrm{~S}$ rRNA clones), [64]. MMG2 sequences were also found in two sponge species: (i) an unidentified poecilosclerid sponge from seeps in the Gulf of Mexico that is morphologically distinct from our samples [28], and (ii) Cladorhiza methanophila from mud volcanoes off Barbados (16-25\% based on 16S rRNA tag sequencing [25]). MOX belonging 


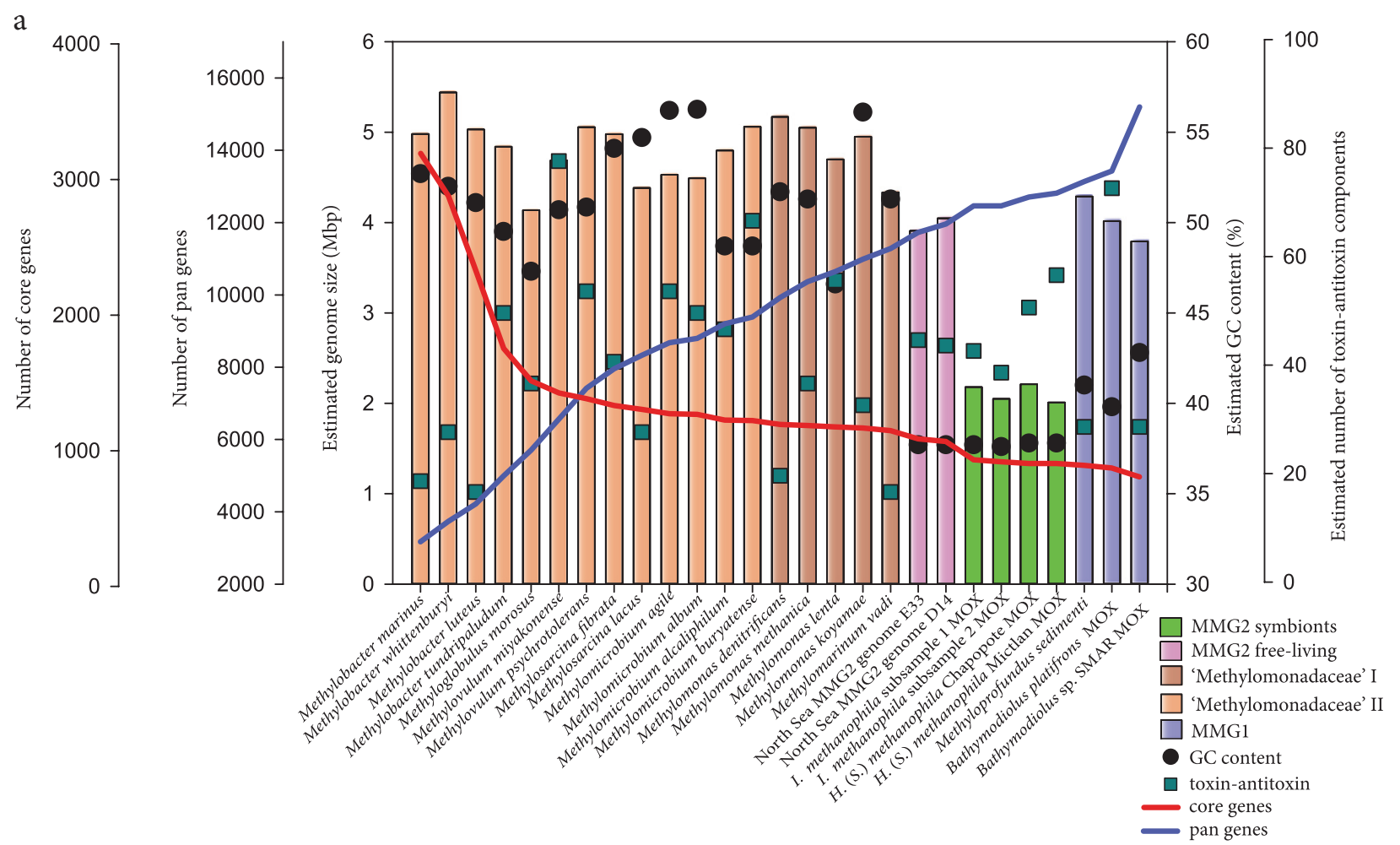

b

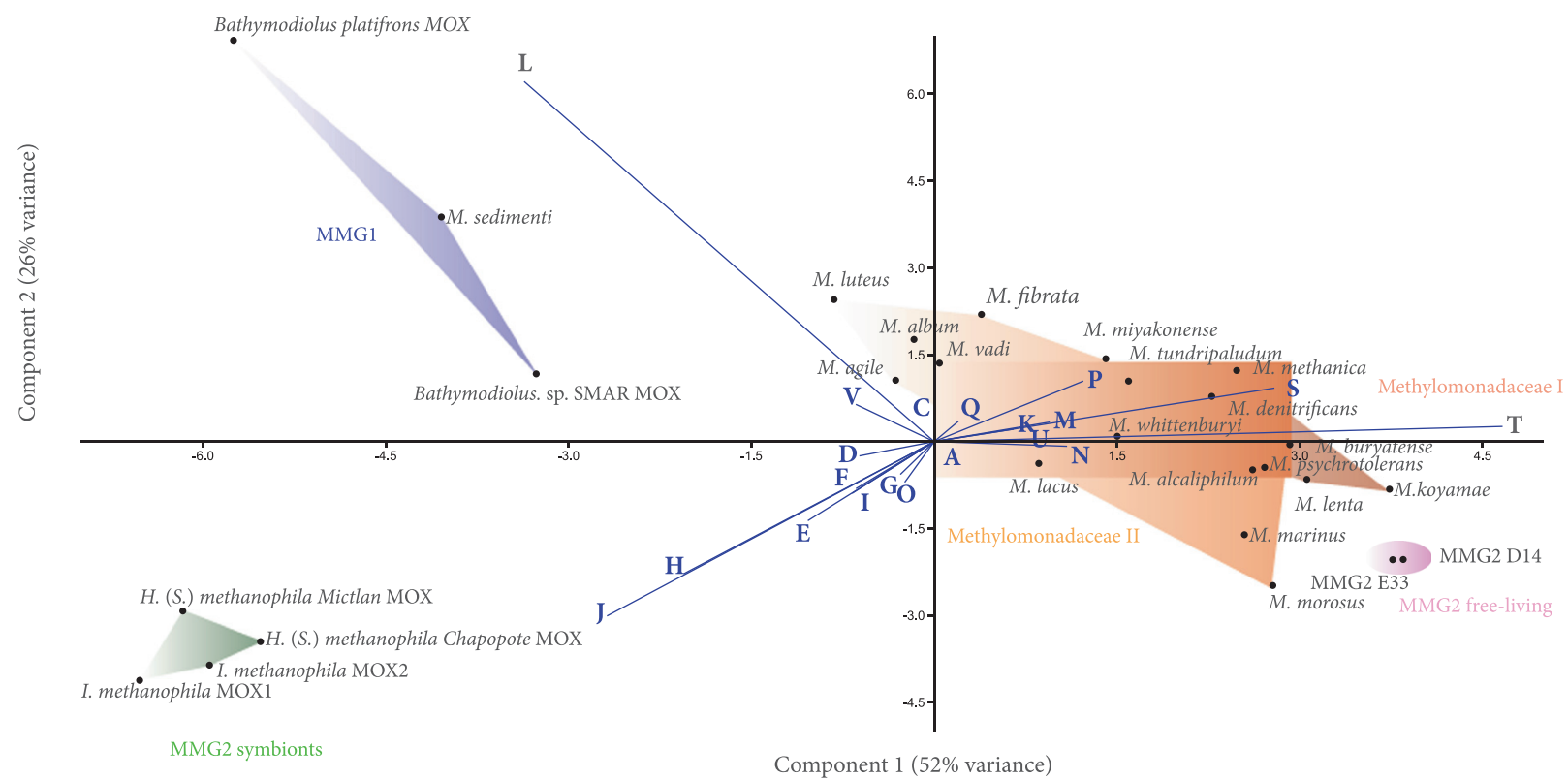

to the MMG2 clade were also found in a Sibolginum cf. poseidoni tubeworm from a mud volcano in the Northeast Atlantic (the nine 16S rRNA clones sequenced from the tubeworm all belonged to MMG2 [65]).

Common to all these hosts is that they occur in methanerich environments, such as mud volcanoes, seeps, and hydrothermal vents, where free-living MMG2 bacteria are known to be abundant in both the sediment and the water column [36]. Given the broad range of hosts associated with bacteria from the MMG2 clade, from protists to animals from different phyla, it is highly likely that these associations were established multiple times independently of each other. Moreover, the MOX bacterial partners in these associations are phylogenetically distinct from those of the deepsea bathymodiolin mussels, which belong to the MMG1 clade (Fig. 4 and Supplementary Figures S3 and S4) [66]. 
Fig. 5 Comparison of genomes from the sponge symbionts and other gammaproteobacterial methane-oxidizing bacteria (MOX). a Distribution of estimated genome sizes, guanine-cytosine (GC) content and the estimated number of toxin-antitoxin components in genomes of methane-oxidizing bacteria (MOX). The blue and red lines show pan genomes (blue) versus core genome (red) development plots (obtained by iteratively adding one genome at a time to the comparison in the defined order (starting with the first genome from the left). Comparative genomic analysis led to a pan-genome estimate of 16476 coding sequences, of which 1050 formed the core genome. The gradual change in the slope of the pan-genome development curve for the MMG 2 symbionts suggests that this clade is sufficiently sampled. 163 genes were subtracted from the core genome of 'Methylomonadaceae' after addition of the sponge symbionts. $\mathrm{Mbp}=$ million base pairs. b Principal component analysis based on the relative abundance of clusters of orthologous groups (COGs) encoded by symbiotic and freeliving MOX. The following COG abbreviations are shown: [D] cell cycle control, cell division, chromosome partitioning, [M] cell wall/ membrane/envelope biogenesis, $[\mathrm{N}]$ cell motility, [O] posttranslational modification, protein turnover, and chaperones, [T] signal transduction mechanisms, $[\mathrm{U}]$ intracellular trafficking, secretion, and vesicular transport, [V] defense mechanisms, [A] RNA processing and modification, $[\mathrm{J}]$ translation, ribosomal structure and biogenesis, $[\mathrm{K}]$ transcription, $[\mathrm{L}]$ replication, recombination and repair, $[\mathrm{C}]$ energy production and conversion, [E] amino acid transport and metabolism, $[\mathrm{F}]$ nucleotide transport and metabolism, [G] carbohydrate transport and metabolism, $[\mathrm{H}]$ coenzyme transport and metabolism, $[\mathrm{I}]$ lipid transport and metabolism, [P] inorganic ion transport and metabolism, [Q] secondary metabolites biosynthesis, transport, and catabolism, [S] function unknown

Our study thus contributes to revealing the previously unrecognized diversity of methanotrophic associations on both the bacterial and host side. This diversity suggests that there are strong selective advantages for both partners in establishing these beneficial associations in methane-rich environments. Revealing the factors that contribute to these selective advantages, and distinguishing these from the mechanisms behind the broad host promiscuity in MMG1 MOX and the apparent specificity of MMG2 MOX to bathymodiolin mussels, will contribute to understanding the ecological and evolutionary requirements for establishing these symbioses.

\section{The symbiotic MOX may be vertically transmitted}

We found evidence for vertical transmission of the symbiotic MOX from one generation to the next. Embryos in the matrix of both $H$. (S.) methanophila individuals contained MOX symbionts based on FISH and TEM analyses (Figs. 2 and 3; Supplementary Figure S5). The symbiotic MOX were observed in the matrix between the embryo cells, but never inside of sponge cells (Fig. 3e). MOX were also found between follicle-like cells surrounding the egg, as well as on the periphery of follicle-like cells (Supplementary Figure S5). In the seep sponge Cladorhiza methanophila, bacteria with features typical of methaneoxidizing bacteria were also observed in embryos with
TEM, indicating that symbionts are transmitted vertically in this sponge species as well [67].

\section{Genome reduction in the symbiotic MOX}

Additional support for our conclusion that the Campeche sponge MOX symbionts are vertically transmitted is provided by the comparison of their genome sizes to those of free-living MOX bacteria. The estimated genome sizes of the Campeche MOX symbionts were between 2.0 and 2.2 $\mathrm{Mbp}$, and thus considerably reduced in comparison to the 3.9 and 4.0 Mbp genomes of their close relatives from North Sea sediment enrichments (Fig. 5a, Supplementary Table S1). The genomes of the sponge MOX symbionts were also reduced in comparison to those of cultivated 'Methylomonadaceae' (4.5-5.2 Mbp), although some freeliving 'Methylomonadaceae' may have similarly small genomes, e.g., Methylococcales bacterium OPU3_GD_OMZ from a marine metagenome [68]. Given that the sponge-associated MOX genomes were highly complete (94.6-96.5\%), it is unlikely that we underestimated their sizes due to incomplete binning (Supplementary Table S1). As genome reduction is typical for vertically transmitted symbionts, the small genome sizes of the Campeche sponge MOX symbionts may be a result of accelerated genome evolution through vertical transmission [69-71]. The very low guanine + cytosine (GC) content of the symbiont genomes $(37.7 \pm 0.1 \%$ versus $51 \pm 4 \%$ in cultivated 'Methylomonadaceae') may also be a result of vertical transmission, as known from many other vertically transmitted symbionts Fig. 5a) [72]. However, the closest freeliving relatives of the sponge symbionts, the North Sea bacteria from sediment enrichments (Fig. 4), have similarly low GC contents of $37.7 \%$, indicating that other factors, such as energetic constraints, may have played a role in the genome evolution of this clade [73, 74].

\section{Optimization of methane assimilation in sponge symbionts}

To better understand the functional adaptations of the sponge MOX to their symbiotic lifestyle, we compared their genomes to those of free-living MOX within the 'Methylomonadaceae' as well as the MOX symbionts of bathymodiolin mussels (Figs. 4 and 5). We identified 1050 genes in the core genome of the free-living 'Methylomonadaceae', 163 of which were not found in the sponge MOX symbionts (Fig. 5a, Supplementary Table 3a). Comparative genomics revealed that the functional repertoire of the sponge MOX symbionts for the assimilation of methane and other carbon compounds was reduced in comparison to free-living bacteria within the 'Methylomonadaceae' (Figs. 4, 5b, Supplementary Figure S6). 


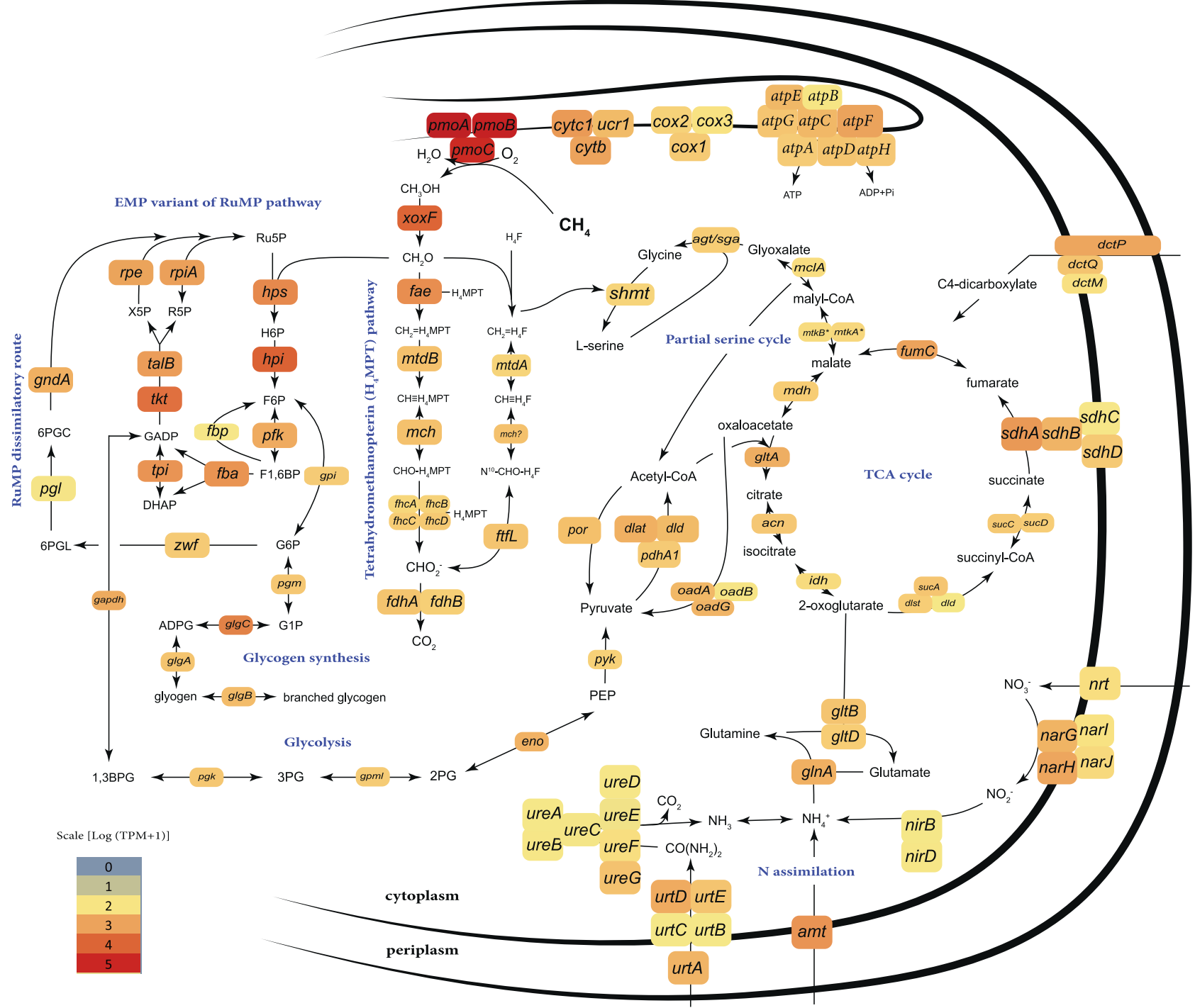

Similar to other 'Methylomonadaceae', the sponge MOX symbionts are type I methanotrophs: The ribulose monophosphate (RuMP) cycle appears to be their sole pathway for methane incorporation, as key enzymes for the assimilatory serine cycle, such as hydroxypyruvate reductase, were not found [75]. Genes not found in the sponge MOX included those encoding the Entner-Doudoroff (EDD) pathway enzymes, phosphogluconate dehydratase (Edd) and 2-dehydro-3-deoxy-phosphogluconate aldolase (Eda), which play a role in methane carbon assimilation via the RuMP pathway [76]. The sponge MOX symbionts appear to assimilate single carbon compounds only via the highly efficient Embden-Meyerhof-Parnas (EMP) variant of the RuMP cycle, based on the presence and substantial expression of the genes encoding fructose-bisphosphate aldolase ( $f b a$ ) and pyrophosphate-dependent phosphofructokinase (pfk) [76] (Fig. 6). The sponge MOX symbionts may, therefore, be more efficient in using single carbon compounds than the methane-oxidizing symbionts of bathymodiolin mussels, which only employ the less efficient EDD variant of the RuMP pathway [76, 77]. This suggests that the symbiotic MOX of sponges are able to provide nutrition to their hosts at lower methane concentrations than the mussel symbionts. This hypothesis is supported by our mapping analyses of the seafloor at Chapopote, as sponges were often situated further from hotspots of active gas and oil seepage than the mussels (Supplementary Figure S2).

The symbiotic MOX appear to use a minimal suite of enzymes needed for methane assimilation. As opposed to most sequenced, free-living MOX, in which two variants of methanol dehydrogenase, the lanthanide-dependent (XoxF) and the calcium-dependent $(\mathrm{MxaF})$ methanol dehydrogenase co-occur, only XoxF was found in the sponge symbionts (Fig. 4). Furthermore, only one pmoCAB operon encoded the methane monooxygenase, while the $\operatorname{pxm} A B C$ operon 
Fig. 6 Central carbon and nitrogen metabolism in the sponge MOX symbionts. The reconstruction is based on the genomes of I. methanophila and $H$. (S.) methanophila symbionts and on the average expression in the two transcriptomes of $H$. (S.) methanophila symbionts. Boxes represent enzyme subunits and the abbreviations represent the genes that encode the respective subunit. Boxes are colored according to the expression value of the gene. The following genes are abbreviated: pmoABC, particulate methane monooxygenase subunits $\mathrm{A}, \mathrm{B}$ and $\mathrm{C}$; $x \circ \mathrm{x} F$, methanol dehydrogenase; $f a e$, formaldehyde activating enzyme; $m t d B$, methylene tetrahydromethanopterin dehydrogenase; mch, methenyltetrahydromethanopterin cyclohydrolase; fhcABCD, formyltransferase/ hydrolase complex; $f d h A B$, formate dehydrogenase subunits alpha and beta; $\quad m t d A$, methylene tetrahydrofolate/methylene tetrahydromethanopterin dehydrogenase; ftfL, formate-tetrahydrofolate ligase; hps, 3-hexulose-6-phosphate synthase; hpi, 6-phospho-3-hexuloisomerase; $p f k$, pyrophosphate-dependent phosphofructokinase; $f b p$, fructose-1,6-bisphosphatase; $f b a$, fructose-bisphosphate aldolase; tpi, triosephosphate isomerase; $t k t$, transketolase; talB, transaldolase; rpe, ribulose-phosphate 3-epimerase; rpiA, ribose-5-phosphate isomerase; gpi, glucose-6-phosphate isomerase; $z w f$, glucose-6-phosphate 1-dehydrogenase; $\quad \mathrm{pgl}, \quad$ 6-phosphogluconolactonase; gndA, 6-phosphogluconate dehydrogenase; gapdh, glyceraldehyde 3-phosphate dehydrogenase; $p g k$, phosphoglycerate kinase; $g p m l, 2,3-$ bisphosphoglycerate-independent phosphoglycerate mutase; eno, enolase; pyk, pyruvate kinase; por, pyruvate-flavodoxin oxidoreductase; dlat, acetyltransferase component of pyruvate dehydrogenase complex; dld; dihydrolipoamide dehydrogenase of pyruvate or 2-oxoglutarate dehydrogenase complexes; $p d h A 1$, pyruvate dehydrogenase E1 component subunit alpha; $o a d A B G$, oxaloacetate decarboxylase, alpha, beta and gamma chains; pgm, phosphoglucomutase; $g \lg C$, glucose-1-phosphate adenylyltransferase; $g \lg A$, glycogen synthase; $\operatorname{glg} B, 1,4$-alpha-glucan branching enzyme; smht, serine hydroxymethyltransferase; agt/sgaA, serine-glyoxylate aminotransferase; $m c l A$, malyl-CoA lyase; $m t k A B$, malate thiokinase, alpha and beta subunits; $m d h$, malate dehydrogenase; gltA, citrate synthase; acn, aconitase; $i d h$, isocitrate dehydrogenase; sucA, 2-oxoglutarate dehydrogenase E1 component; dlst, dihydrolipoyllysine-residue succinyltransferase component of 2-oxoglutarate dehydrogenase complex; sucCD, succinate-CoA ligase subunits beta and alpha; $s d h A B C D$, succinate dehydrogenase complex subunits; fum $C$, fumarate hydratase; dctMPQ, C4-dicarboxylate TRAP transporter subunits; gltDB, glutamate synthase, large and small chains; $g \ln A$, glutamine synthetase; amt, ammonium transporter; nrt, nitrate transporter; nirBD, assimilatory nitrite reductase small and large subunits; narGHIJ, respiratory nitrate reductase, alpha-gamma subunits; urtABCDE, urea $A B C$ transport system subunits; ureABCDEFG, urease subunits; atp $A B C$ $D E F G H$, subunits of the membrane-bound ATP synthase; cox123, cytochrome c oxidase subunit I-III; cytcl, cytochrome c-1, cytochrome b-c1 complex; urcl, cytochrome b-c1 complex subunit 1 ; cytb, cytochrome b, cytochrome b-c1 complex

was not found (Fig. 4). Despite this genetic minimalism in genes involved in methane oxidation, these genes, together with the RuMP pathway, were highly expressed by the symbionts (Fig. 6). Moreover, these genes were among the top $1 \%$ of the most well-expressed transcripts in the metatranscriptomes, which included reads that mapped to both the host and the symbionts. This suggests that methane assimilation by the symbiotic MOX was among the most active metabolic processes in the sponge holobiont.

The sponge MOX symbionts may be able to use other sources of carbon besides methane. Their genomes contained the genes for the TCA cycle, glycogen synthesis and degradation, as well as the import of multicarbon substrates via C4-dicarboxylate tripartite ATP-independent periplasmic (TRAP) transporters (Fig. 6, Supplementary Note 1). Moreover, most of these genes were expressed (Fig. 6). This suggests that similar to the mussel MOX symbionts, which also may use other carbon sources besides methane [77], the sponge MOX symbiont have evolved mechanisms to deal with fluctuations in methane availability. Indeed, our TEM observations of electron-lucent granules typical of carbon storage compounds in the MOX sponge symbionts supports our assumption that glycogen may be used to buffer against periods of methane deprivation.

\section{Reductive evolution and adaptation to the symbiosis}

Comparative analyses of clusters of orthologous groups (COGs) in the sponge MOX with those of free-living 'Methylomonadaceae', as well as the MOX symbionts of bathymodiolin mussels revealed that physical and biotic interactions with the environment appear to have shaped the pan-genome of free-living MOX. In these MOX, functions such as "cell motility", "inorganic ion transport and metabolism", "signal transduction mechanisms", "membrane biogenesis", and "function unknown" (this diverse group includes toxins, type VI secretion system, antibiotic resistance, phage and plasmid proteins) were enriched in comparison to the sponge and mussel symbionts (Fig. 5b). The COGs "translation, ribosomal structure and biogenesis", "coenzyme transport and metabolism" and "amino acid transport and metabolism" were enriched in the sponge MOX symbionts, suggesting that their metabolic repertoire beyond these housekeeping functions is limited. Large numbers of transposases and integrases resulted in the enrichment of the COG "replication, recombination and repair" in the MMG1 clade, which comprises symbionts of bathymodiolin mussels and a single free-living bacterium M. sedimenti. Expansion of transposable elements is more common in symbionts that have recently transitioned to an obligate, host-associated lifestyle, than in symbionts that have associated with their hosts over long evolutionary time periods $[68,69,78,79]$. The sponge symbioses, therefore, may have pre-dated those of mussels. However, this is highly speculative, as the free-living MOX M. sedimenti also has high numbers of transposable elements. The only genes that were shared between the sponge and mussel symbionts, yet not present in most free-living 'Methylomonadaceae', were the narGHIJ genes, encoding enzymes for nitrate respiration (Supplementary Note 2). Thus, there appears to be little convergence in the mechanisms the sponge and mussel symbionts have evolved to establish and maintain associations with their hosts. 
Analysis of the 163 core proteins that were unique to the free-living 'Methylomonadaceae' revealed that the sponge symbionts appear to lack the following functions: (i) nutrient uptake (nitrate $\mathrm{ABC}$ transporter NrtABC, the Pho regulon and phosphate transport system); (ii) secondary metabolite production and secretion ( $\mathrm{Rml}$ proteins that catalyze synthesis of nucleotide/polyketide sugars and Gsp building blocks of the type 2 secretion system); and (iii) adaptation to hypoxia, based on the absence of the highaffinity ba3-type cytochrome oxidase [80] (Fig. 4, Supplementary Table 3a). Further indications that the sponge symbionts are not well adapted to hypoxia was the apparent lack of genes encoding the soluble NAD-reducing hydrogenase and acetate kinase, which catalyze fermentation of methane-derived products in many other MOX [76] (Fig. 4). Some genes and pathways involved in nitrogen metabolism also appear to be lacking in the sponge symbionts. Unlike most free-living MOX, the sponge symbionts may be incapable of nitrogen fixation and dissimilatory nitrite reduction to nitrous oxide (Fig. 4). As suggested previously for sulfur-oxidizing symbionts [81], a divergent respiratory nitrate reductase NarGHIJ, uncommon in most MOX, may play a role in non-canonical nitrate assimilation in the sponge MOX symbionts, which appear to lack the assimilatory nitrate reductase Nas (Supplementary Note 2). Altogether, these findings suggest a reduced functional repertoire of the sponge symbionts, which may have been shaped by (i) adaptation of the sponge MOX to the chemical environment within the host milieu, (ii) metabolic optimization via reduction of functional redundancy, and (iii) a very limited range of biotic interactions with free-living microorganisms. The reduction of such a wide array of functions that appear to be essential for a free-living lifestyle suggests that the sponge MOX may have entered the 'rabbit hole' of obligatory symbiosis, and are no longer able to actively grow outside of their host.

\section{Functional homogeneity between the symbiotic MOX from the two sponge species}

Comparative genomics revealed that the MOX symbionts from the two sponge species were similar in most of their core metabolic pathways. In total, 1042 genes were common to their core genome, while 372 and 357 genes were unique to $H$. (S.) methanophila and I. methanophila symbionts, respectively (Supplementary Figure S6). The main fraction of the genomic content unique to each symbiont consisted of poorly-annotated open reading frames (ORFs), primarily including mobile elements and phage-derived sequences, often stabilized by toxin-antitoxin systems [82]. These toxin-antitoxin systems are abundant in the genomes of all sequenced aerobic methanotrophs and account for a significant part of their genomic variability (Fig. 5a). Only three sets of genes with well-described metabolic functions were present in the genomes of the $H$. (S.) methanophila MOX, but appear to be absent in those of the I. methanophila MOX: (i) genes encoding a urease and urea transporter, (ii) a gene encoding a C4-dicarboxylate transporter, and (iii) a secondary metabolite synthesis cluster, most likely an aryl polyene of unknown function [83] (Supplementary Figure S7). No genes with a well-described metabolic function were found that were unique to the I. methanophila MOX in comparison to the $H$. (S.) methanophila MOX.

\section{Eukaryote-like proteins are encoded in the genomes of the sponge MOX}

The genomes of the sponge MOX symbionts contained 823 genes that were unique to the symbionts from both sponge species, and not present in free-living relatives (97 of which belong the sponge MOX symbiont core genome, see Supplementary Note 3 for more details). Some of these symbiont-specific sequences were ORFs as large as $14.6 \mathrm{~kb}$, and contained one or more eukaryotic-like domains (ELD), such as leucine-rich repeats, cadherin-like domains, and bacterial immunoglobulin-like domains (Supplementary Table S3, Supplementary Figure S8). ORFs with multiple ELDs are well-known from intracellular bacterial pathogens and have also been regularly found in the bacterial metagenomes of other sponge species, where they encode eukaryote-like proteins (ELPs), which are likely involved in symbiotic interactions with their hosts (e.g., ref. [84]). In the MOX symbionts of $H$. (S) methanophila, some of the ELPs contained autotransporter beta-domains. These are known from many gram-negative bacteria, and encode a protein involved in forming a pore through the outer membrane [85]. This suggests that the ELPs could be secreted, providing further evidence for their potential role in symbionthost interactions. BLAST analysis of the sponge MOX symbiont ELPs against the NCBI database resulted in best hits to the ELPs in the Cycloclasticus symbionts of the Campeche sponges (e.g., ORU94421.1, 98\% identity and $78 \%$ coverage compared to the $14.6 \mathrm{~kb}$ ORF from the $H$. (S.) methanophila MOX). The similarity of ELPs from symbionts that inhabit the same host but belong to very distant bacterial lineages suggests the convergent evolution of these putative symbiosis factors.

\section{The symbiotic MOX appear to be the primary source of sponge carbon}

Given the high abundances of MOX symbionts in both Campeche sponge species, we hypothesized that they play an important role in their nutrition. To test this hypothesis, we analyzed phospholipid fatty acids (PLFAs) and sterols in the sponges (see Supplementary Note 4 for more details). 
Table 2 Relative composition of lipid biomarkers and their average $\delta^{13} \mathrm{C}$ values in sponge tissue

\begin{tabular}{|c|c|c|c|c|}
\hline \multirow[t]{2}{*}{ lipid biomarker sources } & \multicolumn{2}{|c|}{ H. (S.) methanophila } & \multicolumn{2}{|l|}{ I. methanophila } \\
\hline & $\%$ of all lipids & $\delta^{13} \mathrm{C}(\% o)(\mathrm{av})$. & $\%$ of all lipids & $\delta^{13} \mathrm{C}(\% o)($ av. $)$ \\
\hline MOX (MUFAs) & 27 & -46 & 14 & -50 \\
\hline Sponge (demospongic acids, MUFAs) & 28 & -47 & 39 & -43 \\
\hline Sponge (sterols) & 29 & -41 & 26 & -43 \\
\hline Various sources (saturated $n$-fatty acids) & 12 & -36 & 16 & -35 \\
\hline Bacteria, usually SRB (tb fatty acids) & 1 & $\mathrm{NM}$ & 1 & $\mathrm{NM}$ \\
\hline Various bacteria (diplopterol) & 3 & -47 & 4 & -43 \\
\hline
\end{tabular}

MOX methane-oxidizing bacteria, SRB sulfate-reducing bacteria, $t b$ terminally-branched, MUFAs monounsaturated fatty acids, $a v$. average, $N M$ not measured
Monounsaturated fatty acids known to be specific to MOX [86], comprised $27 \%$ of all lipids of $H$. (S.) methanophila and $14 \%$ of all lipids in I. methanophila individuals, confirming high abundances of symbiotic MOX in both host species (Table 2). Carbon isotopic signatures of these fatty acids reflected those of Campeche methane $\left(\delta^{13} \mathrm{C}_{\text {methane }}\right.$ was between -50 and $-45 \%$ [32], $\delta^{13} \mathrm{C}_{\text {SpongeMOXfattyacids was }}$ between -51 and $-44 \%$, Supplementary Table S3). This suggests that in contrast to cultivated type I methanotrophs [87, 88], the sponge MOX symbionts, as well as the mussel symbionts [86], do not fractionate methane carbon during the biosynthesis of their fatty acids, possibly due to periodic methane limitation.

We were able to trace elongation of the MOX-specific fatty acids $n$ - $\mathrm{C}_{16: 1 \omega 8}$ and $n$ - $\mathrm{C}_{16: 1 \omega 7}$ to $n$ - $\mathrm{C}_{18}, n-\mathrm{C}_{20}, n-\mathrm{C}_{22}, n$ $\mathrm{C}_{24}, n-\mathrm{C}_{26}$ with the same double bond positions and similar isotopic signatures in $H$. (S.) methanophila. This indicates that carbon compounds from the MOX symbionts were incorporated into their host's biomass (Table 2, Supplementary Table S3). I. methanophila also showed a similar chain-elongation pattern, however, the double bond positions were not exclusively $\omega 8$ and $\omega 7$, suggesting a lower degree of carbon incorporation from its MOX symbionts than in $H$. (S.) methanophila. Given the very low isotopic values of most sponge-derived lipid biomarkers, methane appears to be the main carbon source of the Campeche sponges, and we hypothesize that the majority of the methane-derived carbon in the sponges originates from their symbionts (Supplementary Note 5).

\section{Conclusions}

Our study revealed that two, only distantly related, species of sponges independently established highly specific, nutritional symbioses with two very closely related MOX bacteria. This convergence in symbiont acquisition underscores the strong selective advantage for these sponges in harboring MOX bacteria in the food-limited deep sea: These animals gain access to a carbon and energy source, methane, that they cannot access on their own. For the symbionts, one of the main advantages is that the sponges provide them with simultaneous and continuous access to both methane and oxygen via active water pumping and high surface to volume ratios. In contrast, free-living methanotrophs are limited to a very narrow range of habitats in which methane and oxygen co-occur.

Most research on symbioses between MOX bacteria and eukaryotes has focused on MOX from the MMG1 clade that have, so far, only been found in Bathymodiolus mussels. In contrast, only little is known about the symbioses between MOX from the MMG2 clade and their hosts. The diversity of hosts that these MMG2 MOX are associated with, ranging from ciliates to sponges, lobster and tubeworms, is only beginning to be recognized. Our study provides multifaceted insights into the genomic and metabolic potential of MMG2 MOX symbionts from deep-sea, seep sponges. Future studies of MMG2 MOX from other host groups will allow comparative analyses of the traits that have enabled these bacteria to independently colonize eukaryotic hosts multiple times in convergent evolution.

Acknowledgements The authors thank all individuals who helped during the R/V Meteor research cruise M114, including onboard technical and scientific personnel, the captain and crew, and the ROV MARUM-Quest team. We thank the Max Planck-Genome-Centre Cologne (http://mpgc.mpipz.mpg.de/home/) for generating the metagenomic and the metatranscriptomic data used in this study, the Imaging Core Facility at the University of Würzburg, Germany for embedding of the TEM samples, the Central Microscopy unit at the University of Kiel, Germany for access to their electron microscope facilities, and Ralf Lendt (University of Hamburg) for compoundspecific carbon isotope measurements. We thank Bram Vekeman for providing the genomes from the MMG2 North Sea enrichments. The Campeche Knoll cruise was funded by the German Research Foundation (DFG - Deutsche Forschungsgemeinschaft). Additional support was provided through the MARUM DFG-Research Center/Excellence Cluster "The Ocean in the Earth System" at the University of Bremen. We are grateful to the Mexican authorities for granting permission to conduct this research in the southern Gulf of Mexico (permission of DGOPA: 02540/14 from 5 November 2014). This study was funded by the Max Planck Society, the MARUM DFG-Research Center/ Excellence Cluster "The Ocean in the Earth System" at the University of Bremen, an ERC Advanced Grant (BathyBiome, 340535) and a 
Gordon and Betty Moore Foundation Marine Microbial Initiative Investigator Award to ND (Grant GBMF3811), the DFG Collaborative Research Center 1182 'Origin and Function of Metaorganisms to UH and ND, and the European Union's Horizon 2020 research and innovation program to PC and UH under Grant Agreement No. 679849 ('SponGES'). CPA was supported by a postdoctoral fellowship from the Alexander von Humboldt Foundation.

Author contributions MRB, CPA, DB, JP, DB, HS, UH, and ND conceived the study. HS provided the framework for deep-sea sample collections. YM and IMD provided in situ documentation. MRB, CPA, LS, YCW, CMP, DB, JP, and PC analyzed the samples. MRB wrote the manuscript with contributions from all co-authors.

\section{Compliance with ethical standards}

Conflict of interest The authors declare that they have no conflict of interest.

Publisher's note: Springer Nature remains neutral with regard to jurisdictional claims in published maps and institutional affiliations.

Open Access This article is licensed under a Creative Commons Attribution 4.0 International License, which permits use, sharing, adaptation, distribution and reproduction in any medium or format, as long as you give appropriate credit to the original author(s) and the source, provide a link to the Creative Commons license, and indicate if changes were made. The images or other third party material in this article are included in the article's Creative Commons license, unless indicated otherwise in a credit line to the material. If material is not included in the article's Creative Commons license and your intended use is not permitted by statutory regulation or exceeds the permitted use, you will need to obtain permission directly from the copyright holder. To view a copy of this license, visit http://creativecommons. org/licenses/by/4.0/.

\section{References}

1. Webster NS. Cooperation, communication, and co-evolution: grand challenges in microbial symbiosis research. Front Microbiol. 2014;5:164.

2. Schmitt S, Tsai P, Bell J, Fromont J, Ilan M, Lindquist N, et al. Assessing the complex sponge microbiota: core, variable and species-specific bacterial communities in marine sponges. ISME J. 2012;6:564-76.

3. Thomas T, Moitinho-Silva L, Lurgi M, Björk JR, Easson C, Astudillo-García C, et al. Diversity, structure and convergent evolution of the global sponge microbiome. Nat Commun. 2016;7:11870.

4. Taylor MW, Radax R, Steger D, Wagner M. Sponge-associated microorganisms: evolution, ecology, and biotechnological potential. Microbiol Mol Biol Rev. 2007;71:295-347.

5. Gloeckner V, Wehrl M, Moitinho-silva L, Schupp P, Pawlik JR, Lindquist NL, et al. The HMA-LMA dichotomy revisited: an electron microscopical survey of 56 sponge species. Biol Bull. 2017;227:78-88.

6. Webster NS, Thomas T. The sponge hologenome. MBio. 2016;7: e00135-16.

7. Hentschel U, Piel J, Degnan SM, Taylor MW. Genomic insights into the marine sponge microbiome. Nat Rev Microbiol. 2012;10:641-54.

8. Wilson MC, Mori T, Rückert C, Uria AR, Helf MJ, Takada K, et al. An environmental bacterial taxon with a large and distinct metabolic repertoire. Nature. 2014;506:58-62.
9. Burgsdorf I, Slaby BM, Handley KM, Haber M, Blom J, Marshall $\mathrm{CW}$, et al. Lifestyle evolution in cyanobacterial symbionts of sponges. mBio. 2015;6:e00391-15.

10. Gauthier M-EA, Watson JR, Degnan SM. Draft genomes shed light on the dual bacterial symbiosis that dominates the microbiome of the coral reef sponge Amphimedon queenslandica. Front Mar Sci. 2016;3:00196.

11. Slaby BM, Hackl T, Horn H, Bayer K, Hentschel U. Metagenomic binning of a marine sponge microbiome reveals unity in defense but metabolic specialization. ISME J. 2017;11:2465-78.

12. Ryu T, Seridi L, Moitinho-Silva L, Oates M, Liew YJ, Mavromatis $\mathrm{C}$, et al. Hologenome analysis of two marine sponges with different microbiomes. BMC Genom. 2016;17:158.

13. Fan L, Reynolds D, Liu M, Stark M, Kjelleberg S, Webster NS, et al. Functional equivalence and evolutionary convergence in complex communities of microbial sponge symbionts. Proc Natl Acad Sci USA. 2012;109:E1878-E1887.

14. Gao Z-M, Wang Y, Tian R-M, Wong YH, Batang ZB, AlSuwailem AM, et al. Symbiotic adaptation drives genome streamlining of the cyanobacterial sponge symbiont "Candidatus Synechococcus spongiarum". mBio. 2014;5:e00079-14.

15. Lackner G, Peters EE, Helfrich EJN, Piel J. Insights into the lifestyle of uncultured bacterial natural product factories associated with marine sponges. Proc Natl Acad Sci USA. 2017;114: E347-E356.

16. Liu M, Fan L, Zhong L, Kjelleberg S, Thomas T. Metaproteogenomic analysis of a community of sponge symbionts. ISME J. 2012;6:1515-25.

17. Moitinho-Silva L, Díez-Vives C, Batani G, Esteves AI, Jahn MT, Thomas T. Integrated metabolism in sponge-microxbe symbiosis revealed by genome-centered metatranscriptomics. ISME J. 2017;11:1651-66.

18. Fiore CL, Labrie M, Jarett JK, Lesser MP. Transcriptional activity of the giant barrel sponge, Xestospongia muta holobiont: molecular evidence for metabolic interchange. Front Microbiol. 2015; 6:364.

19. Radax R, Rattei T, Lanzen A, Bayer C, Rapp HT, Urich T, et al. Metatranscriptomics of the marine sponge Geodia barretti: tackling phylogeny and function of its microbial community. Environ Microbiol. 2012;14:1308-24.

20. Moitinho-Silva L, Seridi L, Ryu T, Voolstra CR, Ravasi T, Hentschel U. Revealing microbial functional activities in the Red Sea sponge Stylissa carteri by metatranscriptomics. Environ Microbiol. 2014;16:3683-98.

21. Mori T, Cahn JKB, Wilson MC, Meoded RA, Wiebach V, Martinez AFC. et al. Single-bacterial genomics validates rich and varied specialized metabolism of uncultivated Entotheonella sponge symbionts. Proc Natl Acad Sci USA. 2018;115:1718-23.

22. Jørgensen BB, Boetius A. Feast and famine-microbial life in the deep-sea bed. Nat Rev Microbiol. 2007;5:770-81.

23. Vacelet J, Duport E. Prey capture and digestion in the carnivorous sponge Asbestopluma hypogea (Porifera: Demospongiae). Zoomorphology. 2004;123:179-90.

24. Verhoeven JTP, Kavanagh AN, Dufour SC. Microbiome analysis shows enrichment for specific bacteria in separate anatomical regions of the deep-sea carnivorous sponge Chondrocladia grandis. FEMS Microbiol Ecol. 2017;93:fiw214.

25. Hestetun JT, Dahle H, Jørgensen SL, Olsen BR, Rapp HT. The Microbiome and occurrence of methanotrophy in carnivorous sponges. Front Microbiol. 2016;7:1781.

26. Arellano SM, Lee OO, Lafi FF, Yang J, Wang Y, Young CM, et al. Deep sequencing of Myxilla (Ectyomyxilla) methanophila, an epibiotic sponge on cold-seep tubeworms, reveals methylotrophic, thiotrophic, and putative hydrocarbon-degrading microbial associations. Microb Ecol. 2013;65:450-61. 
27. Tian R-M, Zhang W, Cai L, Wong Y-H, Ding W, Qian P-Y, et al. Genome reduction and microbe-host interactions drive adaptation of a sulfur-oxidizing bacterium associated with a cold seep sponge. mSystems. 2017;2:e00184-16.

28. Nishijima M, Lindsay DJ, Hata J, Nakamura A, Kasai H, Ise Y, et al. Association of thioautotrophic bacteria with deep-sea sponges. Mar Biotechnol. 2010;12:253-60.

29. Petersen JM, Wentrup C, Verna C, Knittel K, Dubilier N. Origins and evolutionary flexibility of chemosynthetic symbionts from deep-sea animals. Biol Bull. 2012;223:123-37.

30. Vacelet J, Boury-Esnault N, Fiala-Medioni A, Fisher CR. A methanotrophic carnivorous sponge. Nature. 1995;377:296.

31. Dubilier N, Bergin C, Lott C. Symbiotic diversity in marine animals: the art of harnessing chemosynthesis. Nat Rev Microbiol. 2008;6:725-40.

32. Sahling H, Borowski C, Escobar-Briones E, Gaytán-Caballero A, Hsu C-W, Loher M, et al. Massive asphalt deposits, oil seepage, and gas venting support abundant chemosynthetic communities at the Campeche Knolls, southern Gulf of Mexico. Biogeosciences. 2016;13:4491-512.

33. Rubin-Blum M, Antony CP, Borowski C, Sayavedra L, Pape T, Sahling H, et al. Short-chain alkanes fuel mussel and sponge Cycloclasticus symbionts from deep-sea gas and oil seeps. Nat Microbiol. 2017;17093:17093.

34. Montanaro J, Gruber D, Leisch N. Improved ultrastructure of marine invertebrates using non-toxic buffers. PeerJ. 2016;4:e1860.

35. Kumar Y, Westram R, Kipfer P, Meier H, Ludwig W. Evaluation of sequence alignments and oligonucleotide probes with respect to three-dimensional structure of ribosomal RNA using ARB software package. BMC Bioinforma. 2006;7:240.

36. Ruff SE, Arnds J, Knittel K, Amann R, Wegener G, Ramette A, et al. Microbial communities of deep-sea methane seeps at Hikurangi continental margin (New Zealand). PLoS ONE. 2013;8: e72627.

37. Duperron S, Halary S, Lorion J, Sibuet M, Gaill F. Unexpected co-occurrence of six bacterial symbionts in the gills of the cold seep mussel Idas sp. (Bivalvia: Mytilidae). Environ Microbiol. 2008;10:433-45.

38. LŞ Y1lmaz, Noguera DR. Development of thermodynamic models for simulating probe dissociation profiles in fluorescence in situ hybridization. Biotechnol Bioeng. 2007;96:349-63.

39. Amann RI, Blinder BJ, Olson RJ, Chisholm SW, Devereux R, Stahl DA. Combination of 16S rRNA-targeted oligonucleotide probes with flow cytometry for analyzing mixed microbial populations. Appl Environ Microbiol. 1990;56:1919-25.

40. Wallner G, Amann R, Beisker W. Optimizing fluorescent in situ hybridization with rRNA-targeted oligonucleotide probes for flow cytometric identification of microorganisms. Cytometry. 1993;14:136-43.

41. Peng Y, Leung HCM, Yiu SM, Chin FYL. IDBA-UD: a de novo assembler for single-cell and metagenomic sequencing data with highly uneven depth. Bioinformatics. 2012;28:1420-8.

42. Seah BKB, Gruber-Vodicka HR. gbtools: interactive visualization of metagenome bins in R. Front Microbiol. 2015;6:1451.

43. Nurk S, Bankevich A, Antipov D, Gurevich A, Korobeynikov A, Lapidus A, et al. Assembling genomes and mini-metagenomes from highly chimeric reads. In: Deng M, Jiang R, Sun F, Zhang X, editors. Res Comput Mol Biol. RECOMB, Lecture Notes in Computer Science, Springer; Berlin, Heidelberg. 2013;7821:158-70.

44. Bankevich A, Nurk S, Antipov D, Gurevich AA, Dvorkin M, Kulikov AS, et al. SPAdes: a new genome assembly algorithm and its applications to single-cell sequencing. J Comput Biol. 2012;19:455-77.

45. Gurevich A, Saveliev V, Vyahhi N, Tesler G. QUAST: quality assessment tool for genome assemblies. Bioinformatics. 2013;29:1072-5.
46. Parks DH, Imelfort M, Skennerton CT, Hugenholtz P, Tyson GW. CheckM: assessing the quality of microbial genomes recovered from isolates, single cells, and metagenomes. Genome Res. 2015;25:1043-55.

47. Liao Y, Smyth GK, Shi W. FeatureCounts: an efficient general purpose program for assigning sequence reads to genomic features. Bioinformatics. 2014;30:923-30.

48. Wagner GP, Kin K, Lynch VJ. Measurement of mRNA abundance using RNA-seq data: RPKM measure is inconsistent among samples. Theory Biosci. 2012;131:281-5.

49. Grabherr MG, Haas BJ, Yassour M, Levin JZ, Thompson DA, Amit I, et al. Full-length transcriptome assembly from RNA-Seq data without a reference genome. Nat Biotechnol. 2011;29:64452.

50. Li B, Dewey CN. RSEM: accurate transcript quantification from RNA-Seq data with or without a reference genome. BMC Bioinforma. 2011;12:323.

51. Wu M, Scott AJ. Phylogenomic analysis of bacterial and archaeal sequences with AMPHORA2. Bioinformatics. 2012;28:1033-4.

52. Edgar RC. MUSCLE: multiple sequence alignment with high accuracy and high throughput. Nucleic Acids Res. 2004;32: 1792-7.

53. Kumar S, Stecher G, Tamura K. MEGA7: molecular evolutionary genetics analysis version 7.0 for bigger datasets. Mol Biol Evol. 2016;33:msw054.

54. Le SQ, Gascuel O. An improved general amino acid replacement matrix. Mol Biol Evol. 2008;25:1307-20.

55. Nichols PD, Guckert JB, White DC. Determination of monosaturated fatty acid double-bond position and geometry for microbial monocultures and complex consortia by capillary GCMS of their dimethyl disulphide adducts. J Microbiol Methods. 1986;5:49-55.

56. Brüning M, Sahling H, MacDonald IR, Ding F, Bohrmann G. Origin, distribution, and alteration of asphalts at Chapopote Knoll, Southern Gulf of Mexico. Mar Pet Geol. 2010;27:1093-106.

57. Moitinho-Silva L, Steinert G, Nielsen S, Hardoim CCP, Wu YC, McCormack GP, et al. Predicting the HMA-LMA status in marine sponges by machine learning. Front Microbiol. 2017;8:1-14.

58. Vacelet J, Donadey C. Electron microscope study of the association between some sponges and bacteria. J Exp Mar Bio Ecol. 1977;30:301-14.

59. Maldonado M. Intergenerational transmission of symbiotic bacteria in oviparous and viviparous demosponges, with emphasis on intracytoplasmically-compartmented bacterial types. J Mar Biol Assoc U Kingd. 2007;87:1701-13.

60. Jain C, Rodriguez-R LM, Phillippy AM, Konstantinidis KT, Aluru S. High-throughput ANI analysis of $90 \mathrm{~K}$ prokaryotic genomes reveals clear species boundaries. Nat Commun. 2018;9:5114.

61. Parks DH, Chuvochina M, Waite DW, Rinke C, Skarshewski A, Chaumeil P-A, et al. A standardized bacterial taxonomy based on genome phylogeny substantially revises the tree of life. Nat Biotechnol. 2018;36:996-1004.

62. Vekeman B, Speth D, Wille J, Cremers G, De Vos P, Op den Camp HJM, et al. Genome characteristics of two novel type I methanotrophs enriched from North Sea sediments containing exclusively a lanthanide-dependent XoxF5-type methanol dehydrogenase. Microb Ecol. 2016;72:503-9.

63. Pasulka AL, Goffredi SK, Tavormina PL, Dawson KS, Levin LA, Rouse GW, et al. Colonial tube-dwelling ciliates influence methane cycling and microbial diversity within methane seep ecosystems. Front Mar Sci. 2017;3:276.

64. Watsuji T, Nakagawa S, Tsuchida S, Toki T, Hirota A, Tsunogai $\mathrm{U}$, et al. Diversity and function of epibiotic microbial communities on the galatheid crab. Shinkaia crosnieri Microbes Environ. 2010;25:288-94. 
65. Rodrigues CF, Hilário A, Cunha MR, Weightman AJ, Webster G. Microbial diversity in Frenulata (Siboglinidae, Polychaeta) species from mud volcanoes in the Gulf of Cadiz (NE Atlantic). Antonie Van Leeuwenhoek, Int J Gen Mol Microbiol. 2011;100:83-98.

66. Petersen JM, Dubilier N. Methanotrophic symbioses in marine invertebrates. Environ Microbiol Rep. 2009;1:319-35.

67. Vacelet J, Fiala-Médioni A, Fisher CR, Boury-Esnault N. Symbiosis between methane-oxidizing bacteria and a deep-sea carnivorous cladorhizid sponge. Mar Ecol Prog Ser. 1996;145:77-85.

68. Padilla CC, Bertagnolli AD, Bristow LA, Sarode N, Glass JB, Thamdrup B, et al. Metagenomic binning recovers a transcriptionally active gammaproteobacterium linking methanotrophy to partial denitrification in an anoxic oxygen minimum zone. Front Mar Sci. 2017;4:23.

69. Moran NA, Plague GR. Genomic changes following host restriction in bacteria. Curr Opin Genet Dev. 2004;14:627-33.

70. Moran NA, Bennett GM. The tiniest tiny genomes. Annu Rev Microbiol. 2014;68:195-215.

71. Salem H, Florez L, Gerardo N, Kaltenpoth M. An out-of-body experience: the extracellular dimension for the transmission of mutualistic bacteria in insects. Proc $\mathrm{R}$ Soc $\mathrm{B}$ Biol Sci. 2015;282:20142957-20142957.

72. Wernegreen JJ. Endosymbiont evolution: predictions from theory and surprises from genomes. Ann N Y Acad Sci. 2015;1360:1635 .

73. Batut B, Knibbe C, Marais G, Daubin V. Reductive genome evolution at both ends of the bacterial population size spectrum. Nat Rev Microbiol. 2014;12:841-50.

74. Mann S, Chen YPP. Bacterial genomic $\mathrm{G}+\mathrm{C}$ compositioneliciting environmental adaptation. Genomics. 2010;95:7-15.

75. Anthony C. The biochemistry of methylotrophs. London, New York: Academic Press; 1982.

76. Kalyuzhnaya MG, Yang S, Rozova ON, Smalley NE, Clubb J, Lamb A, et al. Highly efficient methane biocatalysis revealed in a methanotrophic bacterium. Nat Commun. 2013;4:2785.

77. Ponnudurai R, Kleiner M, Sayavedra L, Petersen JM, Moche M, Otto A, et al. Metabolic and physiological interdependencies in the Bathymodiolus azoricus symbiosis. ISME J. 2017;11:463-77.
78. Hendry TA, Freed LL, Fader D, Fenolio D, Sutton TT, Lopez JV. Ongoing transposon-mediated genome reduction in the luminous bacterial symbionts of deep-sea ceratioid anglerfishes. mBio. 2018;9:e01033-18.

79. Oakeson KF, Gil R, Clayton AL, Dunn DM, Von Niederhausern AC, Hamil C, et al. Genome degeneration and adaptation in a nascent stage of symbiosis. Genome Biol Evol. 2014;6:76-93.

80. Kleiner M, Young JC, Shah M, Verberkmoes NC, Dubilier N. Metaproteomics reveals abundant transposase expression in mutualistic endosymbionts. mBio. 2013;4:16-18.

81. Kleiner M, Wentrup C, Lott C, Teeling H, Wetzel S, Young J, et al. Metaproteomics of a gutless marine worm and its symbiotic microbial community reveal unusual pathways for carbon and energy use. Proc Natl Acad Sci USA. 2012;109:1173-82.

82. Van Melderen L. Toxin-antitoxin systems: Why so many, what for? Curr Opin Microbiol. 2010;13:781-5.

83. Cimermancic P, Medema MH, Claesen J, Kurita K, Wieland Brown LC, Mavrommatis K, et al. Insights into secondary metabolism from a global analysis of prokaryotic biosynthetic gene clusters. Cell. 2014;158:412-21.

84. Díez-Vives C, Moitinho-Silva L, Nielsen S, Reynolds D, Thomas T. Expression of eukaryotic-like protein in the microbiome of sponges. Mol Ecol. 2017;26:1432-51.

85. Desvaux M, Parham NJ, Henderson IR. The autotransporter secretion system. Res Microbiol. 2004;155:53-60.

86. Kellermann MY, Schubotz F, Elvert M, Lipp JS, Birgel D, PrietoMollar X, et al. Symbiont-host relationships in chemosynthetic mussels: a comprehensive lipid biomarker study. Org Geochem. 2012;43:112-24.

87. Summons RE, Jahnke LL, Roksandic Z. Carbon isotopic fractionation in lipids from methanotrophic bacteria: relevance for interpretation of the geochemical record of biomarkers. Geochim Cosmochim Acta. 1994;58:2853-63.

88. Jahnke LL, Summons RE, Hope JM, Des Marais DJ. Carbon isotopic fractionation in lipids from methanotrophic bacteria II: the effects of physiology and environmental parameters on the biosynthesis and isotopic signatures of biomarkers. Geochim Cosmochim Acta. 1999;63:79-93. 